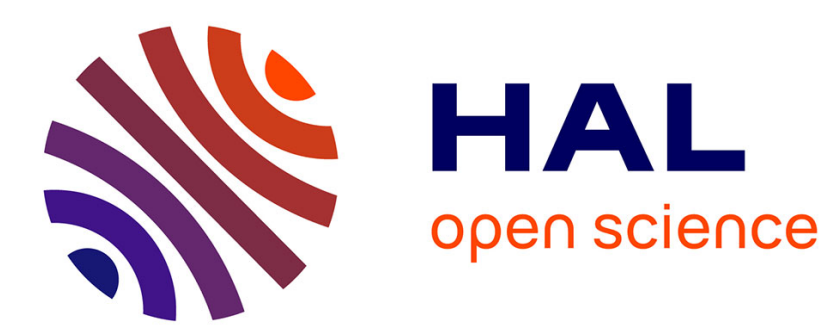

\title{
When fairtrade contracts for some are profitable for others
}

\author{
Claire C. Chambolle, Sylvaine Poret
}

\section{To cite this version:}

Claire C. Chambolle, Sylvaine Poret. When fairtrade contracts for some are profitable for others. European Review of Agricultural Economics, 2013, 40 (5), pp.835-871. 10.1093/erae/jbs039 . hal02642696

\section{HAL Id: hal-02642696 \\ https://hal.inrae.fr/hal-02642696}

Submitted on 28 May 2020

HAL is a multi-disciplinary open access archive for the deposit and dissemination of scientific research documents, whether they are published or not. The documents may come from teaching and research institutions in France or abroad, or from public or private research centers.
L'archive ouverte pluridisciplinaire HAL, est destinée au dépôt et à la diffusion de documents scientifiques de niveau recherche, publiés ou non, émanant des établissements d'enseignement et de recherche français ou étrangers, des laboratoires publics ou privés. 


\title{
When Fairtrade Contracts for some are profitable for
} others*

\author{
Claire Chambolle ${ }^{\dagger \ddagger}$ and Sylvaine Poret ${ }^{\ddagger}$
}

\begin{abstract}
We analyse a vertical chain with perfectly competitive farmers who offer raw products on a spot market to manufacturers who resell the finished goods to a distributor. Absent Fairtrade, the entire raw product is sold on the spot market. A Fairtrade organisation can offer to part of farmers a contract consisting of a guaranteed minimum price and a direct relationship with a distributor. A snowball effect arises when farmers who are not involved in Fairtrade benefit from a higher spot price. This article highlights several mechanisms, either linked to the demand or the market structure, that may explain this snowball effect.
\end{abstract}

Keywords: Fair Trade, Guaranteed Minimum Price, Vertical Chain, Contracts, Disintermediation.

JEL classification: D21, L11, O12.

${ }^{*}$ We gratefully acknowledge support from two chairs of École Polytechnique: Finance Durable et Investissement Responsable and Business Economics and the support of the ANR project OCAD (ANR-11-ALID-xxx002). We thank Nicolas Schutz and participants at the conference on Sustainable Development in Strasbourg (2008), at the meetings of the European Association of Agricultural Economists (2008), the Journées Louis-André Gérard-Varet (2008) and the WEAI Pacific Rim Conference (2009). We also wish to thank three anonymous referees and the Editor, Christoph Weiss, for their very useful comments and suggestions which helped to improve the paper.

${ }^{\dagger}$ INRA, UR1303 ALISS, F-94205 Ivry-sur-Seine, France

${ }_{\ddagger}^{\ddagger}$ Department of Economics, Ecole Polytechnique, F-91128 Palaiseau, France 


\section{Introduction}

The purpose of fair trade is to reduce poverty by establishing an ethical trade channel that enables small farmers from the southern countries to gain access to markets in the northern countries (Renard, 2003; Moore, 2004). A "Fairtrade" label that covers both production and trade conditions was created in 1988 in the Netherlands to promote fair trade products in conventional markets. Currently, the Fairtrade Labelling Organizations (FLO) certify firms that offer a guaranteed minimum price (GMP) to small farmers and that attempt to reduce the number of intermediaries between farmers and consumers (Raynolds, 2000; FLO, 2008). ${ }^{1}$ Most of the farmers who are involved in the fair trade market sell only part (approximately 20\%) of their production through the Fairtrade channel and sell the remainder on the spot market (Renard, 2005). ${ }^{2}$

Fair trade is the target of numerous criticisms. For example, the efficiency of its cooperative governance is often questioned with respect to the efficiency of traditional trade, other ethical alternatives and direct donation. ${ }^{3}$ Other criticisms concern the selection of certified cooperatives, the quality of fair trade products and the definition of a fair price (Booth and Whetstone, 2007; Sidwell, 2008; Henderson, 2008; Griffiths, 2010). The main opposition that is specifically addressed to the FLO system (Fairtrade), is related to the GMP and its potential "oversupply" effect (Smith, 2010). Indeed, several papers argue that the attractive conditions that are offered by the Fairtrade

\footnotetext{
${ }^{1}$ For instance, Fairtrade coffee producers are guaranteed to earn at least US\$1.21 per pound in addition to a premium of US\$0.05. If the coffee spot price is higher than the minimum price, then importers pay the spot price and the premium. In 2002, the average difference between the Fairtrade price and the New York "C" price for Arabica coffees was equal to nearly US\$0.72 per pound (Giovannucci, 2003).

${ }^{2}$ Hereafter, the lower case "fair trade" refers to the global movement, and "Fairtrade" (one word with a capital F) refers to the standards that are associated with the FLO certification.

${ }^{3}$ Reinstein and Song (2012) analyse the latter argument by assuming that a fair trade product is a bundle that includes a base product and a donation. These authors highlight the conditions under which this bundling is efficient.
} 
channel through the GMP provide farmers with incentives to expand their crops and thus increase profits, whereas the Fairtrade organisations frequently do not offer to purchase any surplus (Booth and Whetstone, 2007; Potts, 2007; Sidwell, 2008; Henderson, 2008). This surplus is eventually sold on the spot market, which creates a decrease in spot prices. Finally, only some farmers benefit from Fairtrade through the GMP at the expense of other small farmers. However, Booth and Whetstone (2007) note that this effect has not yet been tested either theoretically or empirically.

In contrast, some field studies highlight the positive indirect effect of Fairtrade on spot prices. ${ }^{4}$ For instance, Milford (2004) studies coffee cooperatives in Chiapas (Mexico) and observes that in the areas in which some cooperatives sell their coffee through the Fairtrade channel, private purchasers offer better prices to farmers outside of these cooperatives. ${ }^{5}$ Bowen (2001: 31 ) also notes that "[...] by paying a fair price for even a small part of production, there is often a snowball effect on prices paid for the rest of production. [...] This effect has been experienced in the case of honey sales in Chiapas in Mexico, Brazil nuts in Peru, cocoa in Bolivia, tea in Zimbabwe etc. This means that not only is it possible for producers who are lucky enough to have made contact with fair trade outlets to sell all their production at better prices, but other producers in the region, often equally marginalized, benefit also." This quote perfectly illustrates the main insight of this article.

Our goal is to investigate the snowball effect on a theoretical basis. Indeed, the GMP sustains the price level for small farmers within a Fairtrade organisation, but by diverting part of the production from the spot market, the GMP can also affect the spot price. ${ }^{6}$ This article highlights

\footnotetext{
${ }^{4}$ Potts (2007) notes that few theoretical or empirical analyses provide insight into the price effects of private voluntary sustainability standard initiatives, such as the Fairtrade certification system.

${ }^{5}$ The same phenomenon is observed in Tanzania (Oxford Management Policy, 2000).

${ }^{6} \mathrm{GMP}$ contracts have been used in the agricultural sector to guarantee farmers income security at a global or national level, including the Australian Wheat Board's GMP scheme (Fraser, 1988). However, our purpose is to study
} 
several arguments that, although not specific to Fairtrade, explain the snowball effect as stated by Bowen (2001). When a snowball effect arises, the small farmers who are not involved in Fairtrade also withdraw a benefit; thus, the results of this study may countervail the oversupply criticism. However, our analysis neutralises the oversupply effect by assumption.

Although our analysis can also be applied to other markets, such as the tea or cocoa markets, we illustrate our model with the flagship product for fair trade: coffee (Poret, 2010; UNCTAD, 2008). We distinguish three main actors: perfectly competitive farmers who grow coffee beans at the upstream level, an oligopoly of roasters who transform and produce the finished coffee at the intermediary level, and a downstream monopsonist distributor who sells the coffee to consumers. ${ }^{7}$ We consider a situation without a fair trade channel as a benchmark. We then introduce a Fairtrade channel that offers small farmers a GMP clause as insurance against bad states of nature (i.e., in case of overproduction) and that eliminates the intermediary by enabling farmers to deal directly with the distributor. We determine the optimal GMP contract offered by the Fairtrade organisation by maximising the expected profits of Fairtrade certified farmers. We then study the effects of the introduction of this channel on the spot price and show that a snowball effect on the spot price could arise and be beneficial to all farmers.

In all of the frameworks studied, we highlight a negative effect related to the GMP offered by the Fairtrade system to the farmers. When a harvest is strong, the spot price decreases, and the GMP becomes operational for the Fairtrade farmers. Thus, the Fairtrade product becomes more expensive, and the distributor increases the Fairtrade retail price in response. This increase leads to a decrease in demand for this specific good. The outcome is a shift of the supply from the Fairtrade this type of contract in another context (i.e., when it is offered in a parallel channel).

${ }^{7}$ Note that McCorriston (2002) urges agricultural economists to account for imperfect competition at the retail level and its effect on farmers. 
channel to the spot market. Thus, this direct "GMP" effect leads to a decrease in the spot price.

To balance this direct negative "GMP" effect, we consecutively consider several mechanisms that explain the snowball effect. We first focus on the influence of the introduction of a Fairtrade product on consumer demand. Two different assumptions are considered. The Fairtrade good is either (i) an additional available variety that increases a consumer's utility by widening his choice set or (ii) a higher-quality good for which consumers are willing to pay a premium with respect to other goods. We show that a snowball effect can arise in both scenarios. Indeed, the introduction of a Fairtrade good increases consumer demand, which in turn raises the spot price. In equilibrium, this positive demand effect is larger than the direct negative "GMP" effect.

Second, our article analyses the effect of the introduction of a Fairtrade channel on the market structure. We show that a snowball effect can arise as a result of (iii) a competition effect or (iv) the disintermediation process. By intensifying competition at the manufacturer level, the entry of a Fairtrade manufacturer increases demand on the spot market, which tends to increase the spot price. Moreover, by suppressing double marginalisation, disintermediation lowers prices in the final market, which tends to increase the demand on the raw market and to increase the spot price. These two positive effects more than compensate for the direct negative "GMP" effect, and this compensation leads to a snowball effect in equilibrium.

Although we acknowledge that none of these effects is specific to Fairtrade, the specificity of a Fairtrade channel may allow these four effects to arise simultaneously; in this case, their cumulative effects would be even stronger. By assumption, we neglect any supply effect, then we show that small farmers can benefit from Fairtrade even if they are not involved in the Fairtrade channel.

Several articles on industrial organisation theory study the influence of contracts between sub- 
groups of producers and distributors on spot prices, and they highlight the contracts by which buyers can exploit market power (Love and Burton, 1999; Xia and Sexton, 2004). These articles usually differ according to the contracts that are considered or the market structure at each level. In general, because these contracts affect both demand and supply, their effect on spot prices is ambiguous. Xia and Sexton (2004) focus on the cattle market and show that top-of-the-market pricing (TOMP) contracts between cattle sellers and packers could restrain buyers from competing aggressively. ${ }^{8}$ TOMP clauses specify that a cattle producer will deliver a given quantity to a buyer at a base price that was established at the highest spot price paid for cattle during a comparison period. In their model, a group of sellers accepts the TOMP contracts from buyers, and these clauses enable the buyers to commit to avoiding aggressive competition with one another; these commitments result in relaxed competition, reduced quantities and a lower spot price.

Some articles, primarily those that address the electricity market, investigate forward market contracts and their influence on the spot market. ${ }^{9}$ Other researchers study the right of first offer, which is a contract clause that prevents a seller from selling an asset to subsequent buyers at a price that is below the price that is offered to the contracted buyer (Hua, 2007). In contrast with our article, this literature focuses on markets in which both sellers and buyers have market power and act strategically.

This article proceeds as follows. Section 2 presents the general assumptions used in the model. Section 3 shows that a snowball effect arises in equilibrium when considering the effect of a Fairtrade product on consumer demand. Section 4 shows that snowball effects also arise in equilibrium through either a competition effect or a disintermediation process. Section 5 concludes.

\footnotetext{
${ }^{8}$ Note that the coffee industry is more complex than the vertical industry that is analysed by Xia and Sexton (2004).

${ }^{9}$ In this framework, it has been argued that having a contract market before the spot market enhances competition in the latter (Allaz and Vila, 1993).
} 


\section{The Model}

We first present the assumptions regarding the market structure, then discuss the assumptions pertaining to demand and finally describe the game.

\subsection{The market structure}

We analyse a three-level vertical chain that includes farmers, manufacturers and a distributor. At the upstream level, farmers are perfectly competitive and offer their raw products to manufacturers. We normalise farmers' production cost to zero. The farmers are not decision makers and thus are assumed to produce only a random harvest. This assumption reflects that the farmers cannot rapidly adapt their production or land capacities or, for instance, the number of trees in the coffee example. More precisely, although there may be some opportunities for short-term expansion with the assistance of unrestricted production factors, further expansion could be prohibitively costly. Therefore, this assumption enables us to avoid any oversupply effect in response to the introduction of the Fairtrade channel.

In the processing industry, manufacturers constitute an oligopoly of size $n$ (with $n \geq 2$ ), and they sell their finished products to a downstream monopsonist distributor who sells the goods to consumers. All production costs are normalised to zero except for the input cost. This framework aims to stylise the main characteristics of the coffee industry. Upstream farmers are green coffee bean producers. The manufacturers who hold the national brands are those who transform the beans into ready-to-drink beverages for consumers (in general roast, instant or decaffeinated coffee). An oligopoly is a good representation of the manufacturers in the coffee processing industry. ${ }^{10}$

\footnotetext{
${ }^{10}$ There is a strong imbalance of power between a large number of small farmers and a few large roasters. The five
} 
Finally, the distributor is a monopsonist in the intermediate market and a monopolist in the final market to reflect the high concentration in the retail sector. Again, retail costs are normalised to zero. ${ }^{11}$

In the Fairtrade channel, the farmers sell directly to the distributor, who sells the Fairtrade product and $n$ national brands.

\subsection{The Demand}

Let us assume that there exist $i=1, \ldots, n$ potential product varieties in the market. If only $m \in$ ] $0, n]$ varieties are available to consumers, (i.e., $i=m+1, \ldots, n$ are not sold if $m<n$ ), ${ }^{12}$, then a representative consumer's utility function is as follows:

$$
U\left(q_{1}, \ldots, q_{i}, \ldots, q_{m}\right)=v \sum_{j=1}^{m} q_{j}-\frac{n}{2}\left((1-\beta) \sum_{j=1}^{m} q_{j}^{2}+\frac{\beta}{n}\left(\sum_{j=1}^{m} q_{j}\right)^{2}\right)
$$

where $v$ is a positive parameter that represents the reservation price, and $q_{i}$ is the quantity of each variety of product $i$ that is sold by the distributor. The parameter $\beta \in(0,1]$ is a measure of product differentiation: higher values of $\beta$ indicate greater closeness in terms of product substitution. We solve $\partial U / \partial q_{i}=p_{i}$ for $i=1, \ldots, m$, where $p_{i}$ denotes the price of product $i$, and we derive the following demand function for each variety $i$ that is offered to a consumer when $n \geq m$ varieties exist on the market:

$$
q_{i}=\frac{v}{(n-\beta(n-m))}-\frac{1}{n(1-\beta)} p_{i}+\frac{\beta}{(n-\beta(n-m)) n(1-\beta)} \sum_{j=1}^{m} p_{j}
$$

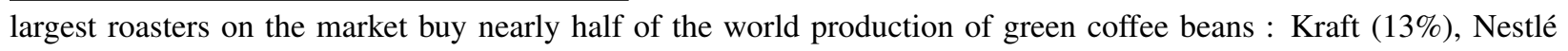
(13\%), Sara Lee (10\%), Procter\&Gamble (4\%), and Tchibo (4\%) (Oxfam, 2002).

${ }^{11}$ Bontems and Bouamra-Mechemache (2004) analyse a similar vertical chain and note that this framework is empirically consistent with the available studies of market structure in the food industry in both Europe and the US.

${ }^{12}$ Some varieties are not available because they are sold out or because entry did not occur (Höffler, 2008). 
and $Q=\frac{m v}{(n-\beta(n-m))}-\frac{\sum_{i=1}^{m} p_{i}}{(n-\beta(n-m))}$. This formulation from Shubik-Levitan (1980) ensures that the parameter $\beta$ captures only product differentiation and has no effect on aggregate demand when all of the brands are offered by the distributor: the total market demand $Q=v-\frac{\sum_{i=1}^{n} p_{i}}{n}$ does not vary with $\beta .^{13}$ Note that when only $m$ products are offered among the $n$ existing products, the aggregated demand for the $m$ products depends on the differentiation parameter $\beta$. Indeed, a stronger differentiation among products is associated with a stronger decrease in the total consumer demand when one product is absent. Moreover, a lower number $m$ of products offered relative to $n$ existing products leads to a lower level of total aggregated demand.

When considering the introduction of a new product on the market, such as a Fairtrade good, two types of model are relevant in terms of a representative consumer's utility.

The first model, which is analysed in Subsection 3.1, is that even when the Fairtrade product is not offered to consumers, this variety exists on the market and consumers are aware of its existence; however, for instance, the Fairtrade organisations may refuse to sell their product to the distributor. ${ }^{14}$ Even absent Fairtrade, a representative consumer's utility accounts for both the $n$ national brands and a Fairtrade variety (i.e., that $n+1$ products exist on the market). Absent Fairtrade, at a maximum, the $n$ national brands are offered, and the representative consumer is thus deprived of the ability to buy the Fairtrade good. With Fairtrade, a representative consumer may now have access to $n+1$ existing varieties.

In a second model, which is employed in the other sections (Sections 3.2 and 4), we assume that in the absence of Fairtrade, only $n$ varieties of the good exist: a representative consumer has not yet heard of Fairtrade. A retailer can sell a maximum of $n$ existing varieties, and a representative

\footnotetext{
${ }^{13}$ See the works of Vives (2001) and Motta (2004) and the note by Höffler (2008) for details.

${ }^{14}$ Another classic debate regarding fair trade involves whether the principles of fair trade themselves are compatible with being sold in supermarkets. See Poret and Chambolle (2007) for an analysis of this issue.
} 
consumer who is not aware of Fairtrade can no longer be deprived of buying it. When Fairtrade is available, the new Fairtrade good is introduced on the market; thus, a representative consumer's utility changes to integrate the existence of the Fairtrade good: there are now $n+1$ existing and potentially available goods on the market.

Furthermore, we alternatively consider that a Fairtrade product is differentiated from any national brand by the parameter $\beta$, similar to the manner in which two national brands are differentiated from one another, or that a representative consumer is prepared to pay a premium for a Fairtrade product, which could be related to vertical differentiation. In such cases, the reservation price for the Fairtrade good is $v^{f}>v$. We will describe and justify these assumptions in greater detail in each subsection.

\subsection{The Game}

We analyse two cases successively: markets with and without the Fairtrade channel. Absent the fair trade channel, the game is the following:

- Stage 1: Farmers incur their production cost (normalised to zero), and the level of the harvest is revealed. $\widetilde{R}$ is a uniformly distributed random variable: $\widetilde{R} \rightsquigarrow U_{\left[0, R^{+}\right]}$where $R^{+}$is equal to $\frac{v}{2}$. This assumption is further justified in the Fairtrade case analysis.

- Stage 2: Offer and demand determine the spot price for the raw product $c$.

- Stage 3: The $n$ brand manufacturers set their two-part tariff contract $\left(w_{i}, T_{i}\right)$ with $i \in$ $[1, \ldots, n]$ and thus maximise their profits. ${ }^{15}$

\footnotetext{
${ }^{15} \mathrm{We}$ also further analyse the alternative assumption in which the retailer offers take-it-or-leave-it two-part tariff contracts to each manufacturer.
} 
- Stage 4: The distributor accepts or refuses each manufacturer's contract and establishes her price $p_{i}$ for each selected brand $i$ that is offered on the final market.

We will then analyse the case in which a Fairtrade product is proposed by a non-profit Fairtrade organisation. This Fairtrade product can be carried by the distributor in addition to the previous $n$ coffee brands. ${ }^{16}$

The "Fairtrade game" is identical to the previous game except that we add the following Stage 0 :

- Stage 0: The Fairtrade certifier establishes his contract price $P$.

We assume that the Fairtrade certifier chooses the GMP $G$ that maximises the expected revenue of the farmers who are involved in the Fairtrade system and that the Fairtrade price $P$ cannot be lower than the spot price. Thus, the Fairtrade wholesale price is defined as follows:

$$
P=\max \left\{G, c^{f}\right\}
$$

where $c^{f}$ is the spot price when there is a Fairtrade channel. In general, the superscript "f" represents the "Fairtrade" case.

- In Stage 4, the distributor accepts or refuses each contract with each manufacturer and the Fairtrade contract with the Fairtrade organisation and offers a retail price $p_{i}$ for each selected

\footnotetext{
${ }^{16}$ The alternative would involve the assumption that the Fairtrade product must replace one of the previous $n$ coffee brands that are sold by the distributor. However, this alternative would lead to an assumption that the distributor has a capacity constraint that prevents it from selling $n+1$ products, and such a constraint would dramatically change the balance of power in favour of the distributor: the latter would be able to credibly threaten each manufacturer with exclusion, wholesale prices would be driven to the marginal cost of production, and the manufacturers would receive zero profits.
} 
brand $i$ and $p^{f}$ for the Fairtrade product if it is selected.

We solve these games in the next two sections.

\section{Demand Effects}

When a Fairtrade product is introduced, consumer demand could increase, but this increase could occur for different reasons: (1) the total demand for a product may increase with the number of products offered by the distributor (variety effect), or (2) the total demand for a product may increase if consumers are willing to pay a higher price for the Fairtrade product compared with a national brand product (premium effect). We analyse the two justifications alternatively using the appropriate specifications of demand.

\subsection{The variety effect}

Here, we assume that there exist $n$ national coffee brands and $f$, a Fairtrade product, in the market. The differentiation between the Fairtrade good and any national brand is $\beta$, which is also the differentiation within any pair of brands. Thus, the Fairtrade good is considered by consumers to be a $n+1^{\text {th }}$ variety of good that is similar to the others. The benchmark "absent fair trade" represents a situation in which the Fairtrade organisation would be selective in their retail channel choice and, for instance, would prefer to avoid sales in supermarkets even at the expense of a large demand loss. Absent fair trade, the Fairtrade product is not offered to consumers, although it could be offered when solving the game "with Fairtrade". We first analyse the benchmark case absent fair trade and then solve the game with Fairtrade. All of the equilibrium values in Subsection ?? are henceforth denoted with an index of "1". 


\subsubsection{Absent fair trade}

In the absence of Fairtrade, although $n+1$ products exist in the market, a maximum of $n$ national brand products can be offered by the distributor to consumers. Using the general expression of the representative consumer utility that is defined by (??), we have for the general case (in which only $i=1, \ldots, m$ and $m \leq n$ brands are offered by the distributor) the following demand function:

$$
q_{i}=\frac{v}{\gamma}-\frac{p_{i}}{(n+1)(1-\beta)}+\frac{\beta \sum_{k=1}^{m} p_{k}}{(n+1) \gamma(1-\beta)} \quad \text { for } i=1, \ldots, m \text { and } m \leq n
$$

where $\gamma=n+\beta(n-m)+(1-\beta)$. When only $m \leq n$ products are offered among the $n+1$ existing products, the aggregated demand now depends on the differentiation parameter $\beta$.

In Stage 4, we assume that the distributor pays $w_{i}$ per unit of product $i$ that is purchased from manufacturer $i$ and a fixed fee $T_{i}$. The monopsonist multi-product distributor chooses the prices $p_{i}$ for each $i \in[1, \ldots, m]$ brand product to maximise its profit function:

$$
\pi^{D}=\sum_{j=1}^{m}\left(\left(p_{j}-w_{j}\right) q_{j}\left(p_{1}, \ldots, p_{m}\right)-T_{j}^{m}\right)
$$

With the first-order conditions, we obtain $p_{i}\left(w_{i}\right)=\frac{v+w_{i}}{2} \quad \forall i=1, \ldots, m$ with $m \leq n$. Let $q_{i}^{m}$ denote the distributor's demand for product $i$ when it sells $m$ products, given the wholesale price vector $\left(w_{1}, \ldots, w_{m}\right)$.

In Stage 3, each of the $i=1, \ldots, n$ brand manufacturers makes its two-part tariff $\left(w_{i}, T_{i}\right)$ takeit-or-leave-it offer to the distributor to maximise its profit under the constraint that the distributor prefers to accept the contract rather than refuse it. Anticipating that $m-1<n$ contracts will be accepted by the retailer in equilibrium, the $m^{\text {th }}$ manufacturer offers a contract such that the following inequality holds:

$$
\sum_{i=1}^{m}\left(p_{i}\left(w_{i}\right)-w_{i}\right) q_{i}^{m}\left(w_{1}, \ldots, w_{m}\right)-\sum_{i=1}^{m} T_{i} \geq \sum_{i=1}^{m-1}\left(p_{i}\left(w_{i}\right)-w_{i}\right) q_{i}^{m-1}\left(w_{1}, \ldots, w_{m-1}\right)-\sum_{i=1}^{m-1} T_{i}
$$


Binding this constraint, we obtain the following:

$$
T_{i}^{m}=\left(p_{i}\left(w_{i}\right)-w_{i}\right) q_{i}^{m}\left(w_{1}, \ldots, w_{m}\right)+\sum_{i=1}^{m-1}\left(p_{i}\left(w_{i}\right)-w_{i}\right)\left(q_{i}^{m}\left(w_{1}, \ldots, w_{m}\right)-q_{i}^{m-1}\left(w_{1}, . ., w_{m-1}\right)\right)
$$

Replacing (??) into the profit of manufacturer $i$ below, we obtain the following:

$$
\pi_{i}^{m}=\left(w_{i}-c\right) q_{i}^{m}\left(w_{1}, \ldots, w_{m}\right)+T_{i}^{m}
$$

where $c$ is the spot price for the raw product; the maximisation program ultimately maximises the profit of a distributor that is vertically integrated with manufacturer $i$ and thus leads to the equilibrium contract:

$$
w_{i}=c \text { and } T_{i}^{m}=\sum_{i=1}^{m}\left(p_{i}(c)-c\right) q_{i}^{m}(c)-\sum_{i=1}^{m-1}\left(p_{i}(c)-c\right) q_{i}^{m-1}(c) \forall i=1, \ldots, m
$$

The tariff above, $T_{i}^{m}$, is the marginal contribution to the industry profit of the $m^{\text {th }}$ brand sold. Because, by assumption, the total industry profit strictly increases with the number of varieties sold, we have $T_{i}>0$ for all $m \leq n$. Furthermore, in equilibrium, all of the contracts are accepted, and the $n$ brands are offered by the distributor. Anticipating this result, each manufacturer obtains its marginal contribution to the industry profit of being the last $\left(n^{\text {th }}\right)$ contract accepted; that is, $T_{i}^{n}=\frac{(1-\beta)(n+1)(v-c)^{2}}{4\left((n+1)^{2}-3 \beta(n+1)+2 \beta^{2}\right)}$.

If we had assumed, rather, that the distributor was offering take-it-or-leave-it two-part tariffs to each manufacturer, then the equilibrium contract would be $w_{i}=c$ and $T_{i}=0$. Because the manufacturers have no outside option profit in our model, the distributor would allow no profit for manufacturers. ${ }^{17}$ Because the wholesale price is not affected, only the sharing of the profits

\footnotetext{
${ }^{17} \mathrm{We}$ have voluntarily chosen the assumption in which manufacturers offer their contracts to the distributor to preserve the notion of profit sharing between an oligopoly of manufacturers and the monopolist retailer, which is more realistic in most industries.
} 
between the manufacturers and the distributor would change, but our main results on the spot price would not be affected.

In equilibrium, total quantity of products that are bought by manufacturers is as follows:

$$
Q^{n}(c)=\frac{n(v-c)}{2(n+1-\beta)}
$$

Equalising the total demand to the harvest $R$, we obtain the following lemma.

Lemma 1. In a market without a fair trade channel with two-part tariff contracts between the $n$ manufacturers and the distributor, the equilibrium spot price is as follows:

$$
c_{1}^{*}(R)= \begin{cases}v-\frac{2(n+1-\beta) R}{n}, & \text { if } R \leq \dot{R}_{1} \\ 0, & \text { if } \dot{R}_{1}<R \leq R^{+} .\end{cases}
$$

We define $\dot{R}_{1}=\frac{v n}{2(n+1-\beta)}<R^{+}$. For any $R>\dot{R}_{1}$, the market clearing price would be negative; thus, we assume that the spot price decreases to zero. ${ }^{18}$ The equilibrium spot price in the absence of the fair trade channel is increasing in $\beta$ because the total market demand is increasing in $\beta$. As we mentioned in Subsection ??, if all of the $n+1$ products are offered to consumers, then the total demand would be independent of $\beta$. Moreover, a larger number of brands $n$ is associated with larger demand on the spot market and thus higher spot prices. Conversely, concentration among manufacturers would decrease the spot price: this relationship between the number of manufacturers and the spot price illustrates the oligopsony power of manufacturers on the raw market. The equilibrium outcomes (profits, surplus and welfare) are given in the Appendix ??.

\subsubsection{With Fairtrade}

Assume now that the distributor sells the Fairtrade product in addition to the $n$ national brands.

\footnotetext{
${ }^{18}$ Here, we assume that the farmers would refuse to pay the manufacturers to buy their raw products.
} 
The quantity and price of the Fairtrade good are denoted as $q^{f}$ and $p^{f}$, respectively; we obtain the following demand functions when $m \leq n$ national brands and the Fairtrade product are sold:

$$
\left\{\begin{aligned}
q_{i} & =\frac{v}{n+1-\beta(n-m)}-\frac{p_{i}}{(n+1)(1-\beta)}+\frac{\beta}{((n+1)-\beta(n-m))(1-\beta)} \frac{\sum_{k=1}^{m} p_{k}+p^{f}}{n+1} \\
q^{f} & =\frac{v}{(n+1)-\beta(n-m)}-\frac{p^{f}}{(n+1)(1-\beta)}+\frac{\beta}{((n+1)-\beta(n-m))(1-\beta)} \frac{\sum_{k=1}^{m} p_{k}+p^{f}}{n+1}
\end{aligned}\right.
$$

By selling a Fairtrade product, the distributor extends the market demand, which increases the total industry profit. However, this Fairtrade product is sold at the unit wholesale price $P$. Thus, the distributor must compare the profit that it receives from selling the Fairtrade product to its cost. The resolution of the game is similar to that of the benchmark case. All of the details are given in the Appendix ??. Let us denote $q^{n, f}(c, P)$ and $q_{i}^{n, f}(c, P)$ as the respective equilibrium quantities of the Fairtrade product and of a brand product $i$, respectively, sold to consumers when $n$ brands and a Fairtrade product are sold and when the spot price is $c$. The spot price when the Fairtrade product is purchased at the same level as the brands, $c_{01}^{f}$, is uniquely defined by the following equality: ${ }^{19}$

$$
R-q^{n, f}\left(c_{01}^{f}, c_{01}^{f}\right)=n q_{i}^{n, f}\left(c_{01}^{f}, c_{01}^{f}\right)
$$

We denote the harvest level by $\widehat{R}_{1}(G)$ such that $G=c_{01}^{f}(R)=v-2 R$, which gives $\widehat{R}_{1}(G)=$ $\frac{v-G}{2} \cdot{ }^{20}$ When $P=G$, the spot price that equalises offer and demand (i.e., such that $R-$ $\left.q^{n, f}(c, G)=n q_{i}^{n, f}(c, G)\right)$ is $c(G, R)=\frac{(n+1)(v-2 R)}{n}$. We also define $\check{R}_{1}(G)=\frac{v}{2}-\frac{G}{(2(n+1))}$ as the level of harvest such that $c(G, R)=0$.

In Stage 0, the Fairtrade certifier chooses the equilibrium GMP, $G_{1}^{*}$, before nature chooses $R$. We assume here that the certifier chooses the GMP to maximise the expected profits of the Fairtrade-certified farmers. ${ }^{21}$ We assume that $G$ is such that there is always a positive quantity

\footnotetext{
${ }^{19}$ Note that $c_{01}^{f}$ is unique, as $q^{f}(c, P)+n q_{i}^{f}(c, P)$ strictly decreases both in $P$ and $c$.

${ }^{20}$ Note here that the condition $R \leq R^{+}=\frac{v}{2}$ is the condition such that $c_{01}^{f}(R) \geq 0$. Thus, a focus on the range of values for the harvest in the interval $\left[0, R^{+}\right]$enables us to consider the most interesting cases.

${ }^{21}$ See Poret and Chambolle (2007) for a discussion regarding the objectives of the Fairtrade certifier.
} 
of Fairtrade products sold to the distributor, i.e., $R \in\left[0, R^{+}\right]$- assumption $(i)$. In this case, the Fairtrade certifier's program is as follows:

$$
\begin{aligned}
\mathbb{E}\left(\pi^{f}(G)^{i}\right)= & \int_{0}^{\widehat{R}_{1}(G)} c_{01}^{f}(R) q^{n, f}\left(c_{01}^{f}(R), c_{01}^{f}(R)\right) d R+\int_{\widehat{R}_{1}(G)}^{\check{R}_{1}(G)} G q^{n, f}(c(G, R), G) d R \\
& +\int_{\check{R}_{1}(G)}^{R^{+}} G q^{n, f}(0, G) d R
\end{aligned}
$$

where $q^{n, f}\left(c_{01}^{f}(R), c_{01}^{f}(R)\right)=\frac{R}{n+1}, q^{n, f}(c(G, R), G)=\frac{v-2 \beta R-G}{2(1-\beta)(n+1)}$, and

$q^{n, f}(0, G)=\frac{(1-\beta)(n+1) v-G(n+1-\beta)}{2(1-\beta)(n+1)^{2}}$.

There is always an interior solution: $G_{1}^{*}=\frac{2 v(1-\beta)(n+1)^{2}}{4(n+1)^{2}-\beta\left(4+2 n+n^{2}\right)}$. We verify that the distributor always sells the Fairtrade product for all $R \in\left[0, R^{+}\right]$.

Lemma 2. In a market with a Fairtrade channel and with two-part tariff contracts between the $n$ manufacturers and the distributor,

- the equilibrium GMP is $G_{1}^{*}=\frac{2 v(1-\beta)(n+1)^{2}}{4(n+1)^{2}-\beta\left(4+2 n+n^{2}\right)}$,

- the equilibrium spot price is equal to

$$
c_{1}^{f}(R)= \begin{cases}c_{01}^{f}(R)=v-2 R & \text { if } R<\widehat{R}_{1}\left(G_{1}^{*}\right) \\ c_{11}^{f}(R)=\frac{(v-2 R)(n+1)-G_{1}^{*}}{n} & \text { if } \widehat{R}_{1}\left(G_{1}^{*}\right) \leq R<\check{R}_{1}\left(G_{1}^{*}\right) \\ 0 & \text { if } \check{R}_{1}\left(G_{1}^{*}\right) \leq R<R^{+}\end{cases}
$$

- the equilibrium Fairtrade price is $P_{1}^{*}=\max \left\{G_{1}^{*}, c_{01}^{f}\right\}$.

When all of the potential varieties are sold and when the Fairtrade product is sold at a price that is equal to that of the other varieties $\left(w_{i}=c_{01}^{f}\right)$, we have the property of the Shubik-Levitan formulation that ensures that the market size (and therefore the spot price $c_{01}^{f}$ ) is independent of the parameters $\beta$ and $n$.

An analytical comparison with the benchmark absent fair trade yields the following proposition: 
Proposition 1. When demand increases with the number of product varieties that are offered, a snowball effect of Fairtrade on the spot price arises in equilibrium when $R<\check{R}_{1}\left(G_{1}^{*}\right)$. All of the farmers sell their harvests at a strictly higher spot price; thus, their profits are increased.

Proof. See Appendix ??.

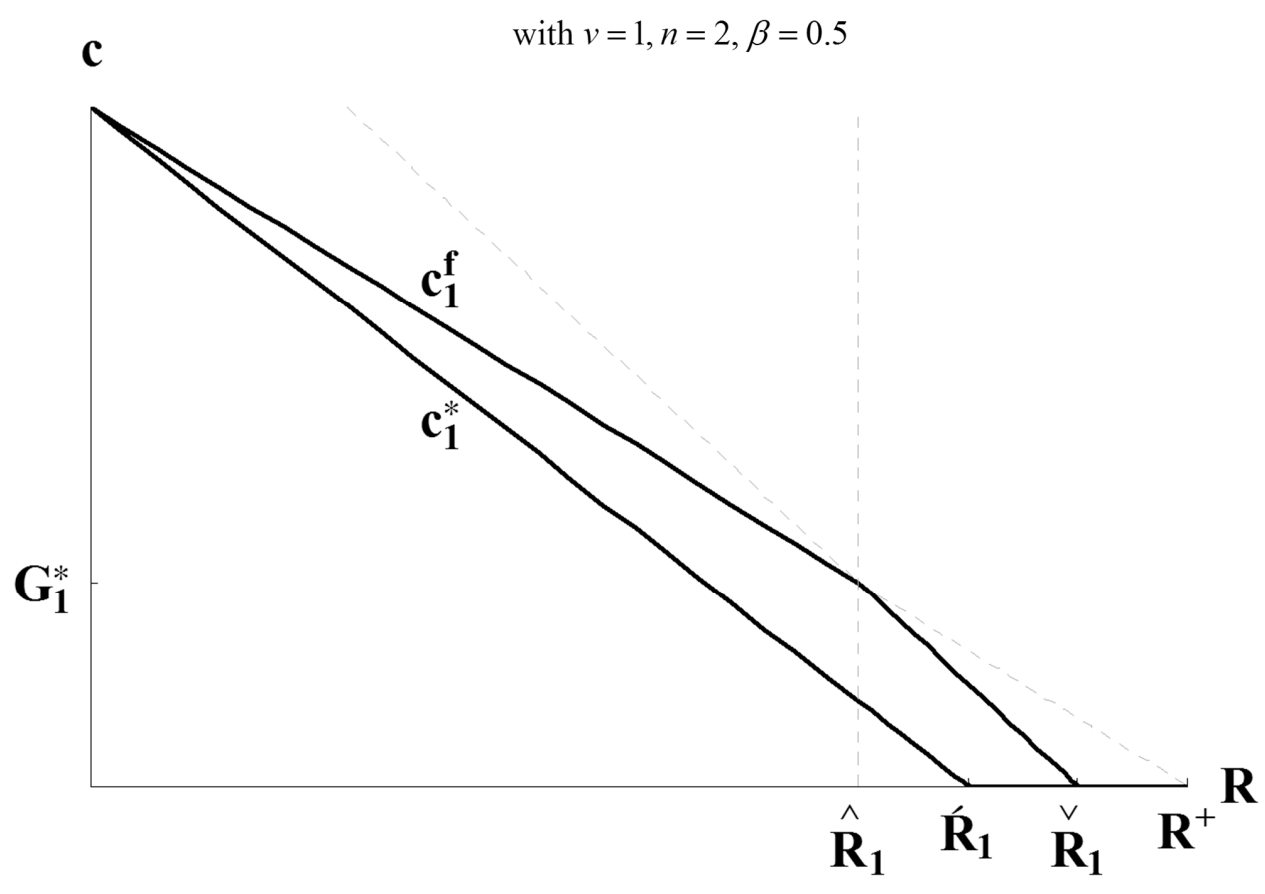

Figure 1: Variety effect

Figure 1 represents the equilibrium spot prices both with and without Fairtrade. In the plane $(R, c)$, the bottom line depicts the spot price in a market absent fair trade, $c_{1}^{*}$, and the top curve represents the spot price with Fairtrade, $c_{1}^{f}$, which is equal to $c_{01}^{f}, c_{11}^{f}$ or 0 , according the level of harvest (see Equation (??)).

The general insight regarding this proposition is as follows. First, the introduction of Fairtrade leads to the introduction of a new variety that increases the total demand for the Fairtrade product. 
By increasing the global demand on the final market, this "variety" effect also increases the demand for the raw product on the intermediate market and thus increases the equilibrium spot price. This effect is captured by the difference between $c_{1}^{*}$ and $c_{01}^{f}$. This effect is not specific to fair trade. We would obtain this positive effect considering any new manufacturer entering the market and offering a new variety of product to the distributor. Second, when the harvest is relatively high $\left(R>\widehat{R}_{1}\left(G_{1}^{*}\right)\right)$, the GMP becomes operational in the Fairtrade channel $\left(P_{1}^{*}=G_{1}^{*}\right)$. Then, the retail price for the distributor is higher for the Fairtrade good than for the brand products. Thus, the demand for the Fairtrade product decreases $\left(q^{n, f}(c, G)\right)$, and this decreased demand induces a supply increase in the spot market $\left(R-q^{n, f}(c, G)\right)$ and, therefore, a decrease in the spot price from $c_{01}^{f}$ to $c_{11}^{f}$. We refer to this Fairtrade-specific effect as the negative "GMP" effect. This effect can be viewed as a part of the oversupply criticism that is underlined in the introduction. This effect is not related to an exogenous increase in the production because farmers have additional capacities of land readily available. Rather, the "GMP" effect is caused by an endogenous shifting of the supply from the Fairtrade channel to the spot market.

Balancing the direct, negative "GMP" effect and the positive demand effect, we show that a strictly positive snowball effect arises when $R<\check{R}_{1}\left(G_{1}^{*}\right)$ in equilibrium. When $\check{R}_{1}\left(G_{1}^{*}\right)<R<$ $R^{+}$, the spot price decreases to zero both with and without Fairtrade. ${ }^{22}$

Comparing welfare with and without fair trade, we find that unless the harvest $\mathrm{R}$ is close to $R^{+}$, the introduction of a Fairtrade channel through the "variety" effect lowers the consumer surplus. ${ }^{23}$ For a given spot price, consumers are always in a better position when the Fairtrade "variety" is sold: there is one additional product from which to choose. However, the introduction of the Fairtrade good increases the spot price, which tends to increase the final prices of all of the goods

\footnotetext{
${ }^{22}$ Indeed, $\check{R}_{1}\left(G_{1}^{*}\right)>\dot{R}_{1}$.

${ }^{23}$ See Appendix ??.
} 
that are sold to consumers. This negative effect outweighs the first positive effect, but consumers may benefit from the introduction of a new product when $R$ is close enough to $R^{+}$(therefore, the snowball effect is rather limited). Comparing the profits at each level of the vertical chain, we find that the farmers and the distributor capture the entire benefit of the introduction of the Fairtrade product to the detriment of the manufacturers. ${ }^{24}$

\subsection{The Premium Effect}

Fairtrade products are associated with a certain quality of trade relationships. Thus, some consumers are willing to pay more to ensure that an organisation treats producers in a fair and ethical manner (Mann, 2008). Indeed, using contingent valuation techniques to estimate the willingness of consumers to pay for the fair trade attribute, Loureiro and Lotade (2005) find that $85 \%$ of consumers are willing to pay a positive premium for fair trade coffee: the average consumer is willing to pay 21.64 cents per pound more for fair trade coffee than for conventional coffee. ${ }^{25}$ We retain the representative consumer's utility function that is defined by Equation (??) but introduce two small changes. In contrast with the previous subsection and to eliminate the "variety" effect that is highlighted in Subsection ??, we now assume that without fair trade, the total number of existing and potentially offered products is $n$, and if a Fairtrade channel is created, there are $n+1$ existing and potentially offered products: in this scenario, all existing products are always potentially offered by the distributor. Moreover, we introduce a parameter $v^{f}>v$, which reflects the willingness

\footnotetext{
${ }^{24}$ The existence of the Fairtrade channel reduces the weight of each manufacturer in the industry profit and thus the equilibrium tariff.

${ }^{25}$ According to Mahé (2010), the premium that consumers are willing to pay for the Fairtrade label for bananas is between $40 \%$ and $60 \%$ of the price per kilo. This experimental study was conducted in 2005 in Switzerland, where Fairtrade products have demonstrated particularly strong success.
} 
of consumers to pay a higher price for a Fairtrade product due to its intrinsic attributes. The premium $\left(v^{f}-v\right)$ reflects the surplus that consumers withdraw from the consumption of a Fairtrade good rather than from a traditional brand and which appears here as a vertical differentiation. We now alternatively solve the game both with and without fair trade.

Note that all of the equilibrium values in Subsection ?? are denoted with an index of "2".

\subsubsection{Absent fair trade}

Absent a fair trade product, if $i=m+1, \ldots, n$ are not sold by the distributor, then the representative consumer's utility function is Equation (??), and the individual demand is given by Equation (??).

The resolution of the game is similar to that in the previous subsection. Maximising the distributor's profit, we have $p_{i}=\frac{\left(v+w_{i}\right)}{2}$ for $i=1, \ldots, n$. Maximising their profit, the manufacturers set $w_{i}=c$ and $T_{i}^{n}=\frac{(1-\beta)(v-c)^{2}}{4(n-\beta)}$. The total industry profit is always maximised when all of the varieties are sold; thus, the distributor offers $n$ varieties. Thus, the total demand for the raw product is $Q^{n}(c)=\frac{v-c}{2}$. Clearing the spot market gives the spot price $c_{2}^{*}(R)=v-2 R$, which decreases with the harvest level and is positive for $R \leq R^{+}$. Because all of the potential varieties are sold, the property of the Shubik-Levitan demand ensures that the parameters $\beta$ and $n$ have no effect on the total demand and thus on the spot price.

\subsubsection{With Fairtrade}

When the Fairtrade product is sold, if products $i=m+1, \ldots, n$ are not sold by the distributor (i.e., the distributor does not sell the $i=m+1, \ldots, n$ national coffee brands but sells the Fairtrade 
product), then the representative consumer's utility function is as follows:

$$
\begin{aligned}
U\left(q_{1}, \ldots, q_{i}, \ldots, q_{m}, q^{f}\right)= & v \sum_{j=1}^{m} q_{j}+v^{f} q^{f} \\
& \left.-\frac{(n+1)}{2}\left((1-\beta)\left(\sum_{j=1}^{m} q_{j}^{2}+\left(q^{f}\right)^{2}\right)+\frac{\beta}{(n+1)}\left(\sum_{j=1}^{m} q_{j}+q^{f}\right)\right)^{2}\right) .
\end{aligned}
$$

We obtain the following demand functions:

$$
\left\{\begin{aligned}
q_{i} & =\frac{1}{(n+1)(1-\beta)}\left[\frac{(n+1)(1-\beta)+\beta}{\gamma+1} v-\frac{\beta}{\gamma+1} v^{f}-p_{i}+\frac{\beta}{(\gamma+1)}\left(\sum_{k=1}^{m} p_{k}+p^{f}\right)\right] \quad \text { for } i=1, \ldots, m ; \\
q^{f} & =\frac{1}{(n+1)(1-\beta)}\left[\frac{\gamma+1-\beta}{\gamma+1} v^{f}-\frac{m \beta}{\gamma+1} v-p^{f}+\frac{\beta}{(\gamma+1)}\left(\sum_{k=1}^{m} p_{k}+p^{f}\right)\right]
\end{aligned}\right.
$$

with $\gamma+1=(n+1)(1-\beta)+(m+1) \beta$.

Maximising the distributor's profit with respect to the final prices, we have $p_{i}=\frac{\left(v+w_{i}\right)}{2}$ for $i=1, \ldots, m$ brand products and $p^{f}=\frac{\left(v^{f}+P\right)}{2}$. Maximising their profit, the brand manufacturers set $w_{i}=c$. Because, as in Subsection 3.1, all of the manufacturers' contracts are accepted in equilibrium by the distributor, we have $T_{i}^{n, f}=\frac{c\left(1+n(1-\beta)+(n+1) v-\beta\left(n v+v^{f}-P\right)\right)^{2}}{4(1-\beta)(n+1-\beta)(n+1)^{2}}$. Thus, the total demand for the raw product is $Q^{n, f}=\frac{n v+v^{f}-n c-P}{2(n+1)}$.

We denote the optimal level of the Fairtrade price as $P_{2}^{*}$ and the optimal level of the GMP as $G_{2}^{*}$. We define $c_{02}^{f}(R)$ as the equilibrium for the spot market when $G_{2}^{*}$ is equal to the spot price, $c_{02}^{f}(R)=\frac{n v+v^{f}}{n+1}-2 R$. Maximising the expected profits of the Fairtrade-certified farmers with respect to $G$, we obtain the following lemma. ${ }^{26}$

Lemma 3. The optimal Fairtrade price $P_{2}^{*}$ is such that a positive quantity of Fairtrade product is sold regardless of the harvest level, and this price is defined as follows: $P_{2}^{*}=\max \left(c_{02}^{f}, G_{2}^{*}\right)$ where

$$
G_{2}^{*}= \begin{cases}\frac{2(n+1) v^{f}-\beta\left(v(1+2 n)+v^{f}\right)}{(4-\beta)(n+1)} & \text { if } v^{f}>\widehat{v}^{f}=\frac{((4(n+1)-\beta(3 n+2)) v}{2+(2-\beta) n} . \\ \frac{(n+1-\beta)(n+3) v^{f}-\left(2(n+1)+\beta\left(n^{2}+n-2\right)\right) v+\frac{1}{2} \sqrt{Y}}{4(n+1)^{2}-\beta(4+n(2+n))} & \text { if } v^{f} \leq \widehat{v}^{f} .\end{cases}
$$

\footnotetext{
${ }^{26}$ See Appendix ?? for details regarding the resolution.
} 
with $Y=4\left(\left(2(n+1)+\beta\left(n^{2}+n-2\right)\right) v-(n+1-\beta)(3+n) v^{f}\right)^{2}+8(\beta(4+n(2+n))-4(n+$ $\left.1)^{2}\right)\left(v^{f}-v\right)\left((n+1) v^{f}-\beta\left(n v+v^{f}\right)\right)$.

Thus, the resulting equilibrium spot price is given in the following lemma.

Lemma 4. The equilibrium spot price after the introduction of the Fairtrade product is as follows:

- when $v^{f}>\widehat{v}^{f}$

$$
c_{2}^{f}= \begin{cases}c_{02}^{f}(R) & \text { if } R \leq \widehat{R}_{2}\left(G_{2}^{*}\right) \\ c_{12}^{f}(R)=\frac{n v+v^{f}-2(n+1) R-G_{2}^{*}}{n} & \text { if } \widehat{R}_{2}\left(G_{2}^{*}\right)<R \leq \check{R}_{2}\left(G_{2}^{*}\right) \\ 0 & \text { if } \check{R}_{2}\left(G_{2}^{*}\right)<R \leq R^{+}\end{cases}
$$

- when $v^{f} \leq \widehat{v}^{f}$

$$
c_{2}^{f}= \begin{cases}c_{02}^{f}(R) & \text { if } R \leq \widehat{R}_{2}\left(G_{2}^{*}\right) \\ c_{12}^{f}(R) & \text { if } \widehat{R}_{2}\left(G_{2}^{*}\right)<R \leq R^{+} .\end{cases}
$$

Comparing the equilibrium spot price both with and without fair trade, we obtain the following:

Proposition 2. When consumers are willing to pay a premium for a Fairtrade product, the market size increases when the Fairtrade product is introduced, and a snowball effect arises in equilibrium when $R<R_{2}^{S}$.

Proof. See Appendix ??.

As shown previously, Figure 2 represents the equilibrium spot prices both with and without Fairtrade. The general insight regarding this proposition is as follows. In Subsection ??, without the premium, the introduction of the Fairtrade channel creates a new variety, which, in itself and in contrast with the Subsection ??, does not increase the total demand for the product: rather, the 


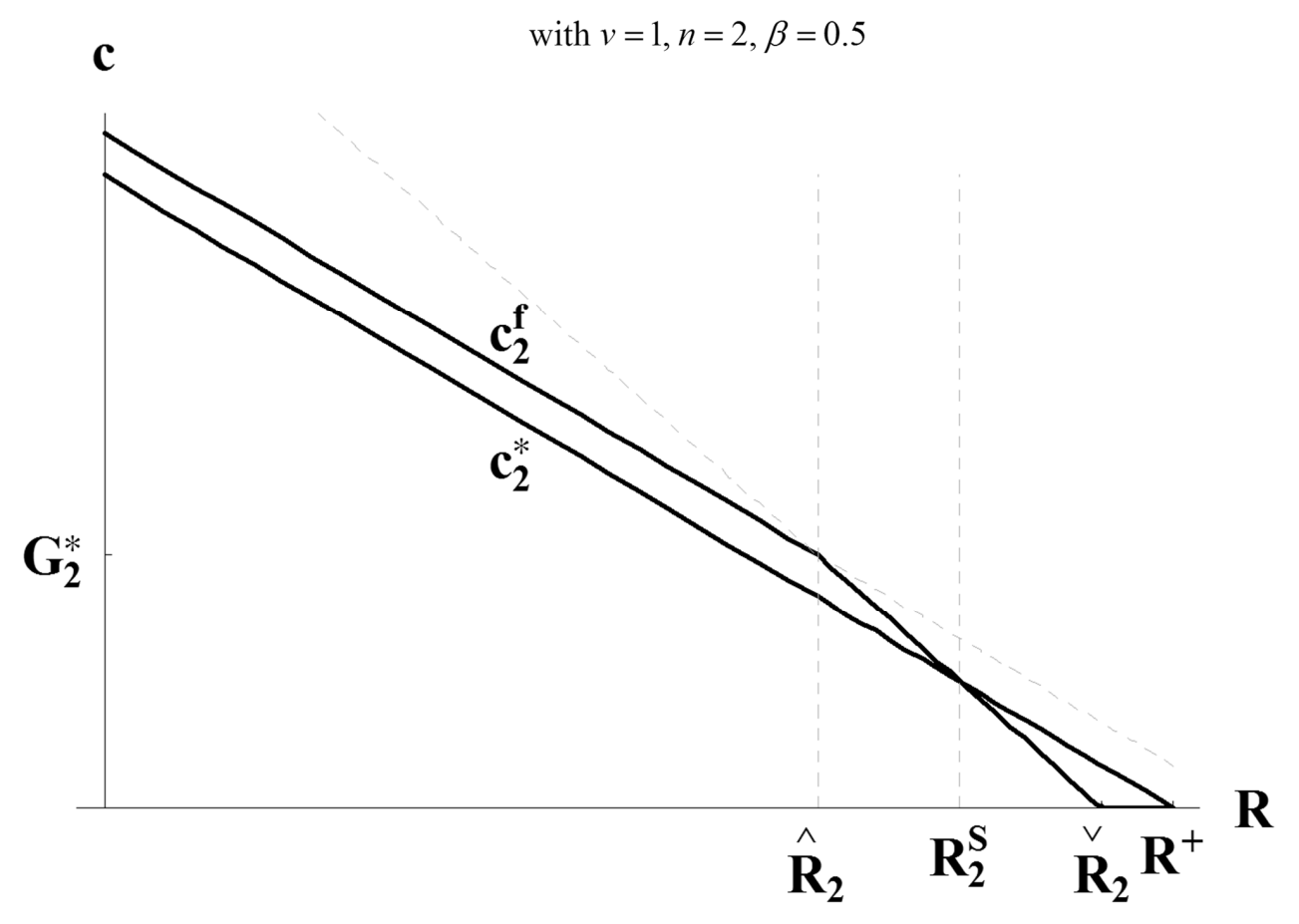

Figure 2: Premium effect

demand for each product is lowered, with the total demand held constant. Thus, absent a premium, the introduction of the Fairtrade channel would have no effect on the spot price. ${ }^{27}$ By increasing global demand on the final market, the "premium" effect also increases the demand for the raw product in the intermediate market and thus increases the equilibrium spot price. This effect is captured by the difference between $c_{2}^{*}(R)$ and $c_{02}^{f}(R)$. This "premium" effect is not specific to Fairtrade and could apply to any product that holds a specific attribute that is valued by consumers.

As in Subsection ??, when the harvest is large $\left(R>\widehat{R}_{2}\right)$, the GMP becomes operational $\left(P_{2}^{*}=G_{2}^{*}\right)$, and the retail price is higher for the Fairtrade good than for the brands that generate the negative "GMP" effect. In contrast with the previous section, when $R>R_{2}^{S}$, the negative "GMP" effect outweighs the positive "premium" effect, and the equilibrium spot price decreases

\footnotetext{
${ }^{27}$ In the particular case in which $v^{f}=v, c_{02}^{f}(R)=v-2 R=c_{2}^{*}$; thus, the snowball effect entirely disappears absent the "premium" effect.
} 
after the introduction of the Fairtrade product. $R_{2}^{S}$ strictly decreases with $\beta$ as the lower interbrand competition the higher price of the Fairtrade good, which reinforces the negative "GMP" effect. As long as Fairtrade is sold, Fairtrade farmers receive increased "revenue" by comparison with other farmers. However, the Fairtrade premium $v^{f}$ that consumers are willing to pay for Fairtrade is not entirely transmitted to the farmers, and the distributor also retains part of this premium.

\section{Market Structure Effects}

This section shows that the introduction of a Fairtrade channel may influence the market structure in two different ways. First, the introduction of a Fairtrade channel implies the entry of a new manufacturer (which is symmetric to all of the other manufacturers) on the intermediate market, and this entry creates a "competition" effect. Second, because the distributor can directly purchase Fairtrade products from farmers through the Fairtrade organisation, this new channel is a short supply channel, which creates a "disintermediation" effect.

We consider here that the Fairtrade product is a new product that does not exist in the benchmark case, as in Subsection ??. The representative consumer's utility functions are then Equations (??) and (??) with $v^{f}=v$. The corresponding demand functions are Equations (??) and (??) with $v^{f}=v{ }^{28}$ These assumptions enable us to highlight only the structural effects and thus to neglect the demand effects that were previously studied. The games both with and without fair trade are the same as those previously described, except for one assumption: in Stage 3, the manufacturers now offer take-it-or-leave-it linear tariff contracts $\left(w_{i}\right)$ for $i=1, \ldots, n$, where $w_{i}$ is the unit wholesale price as in the previous cases. Indeed, we explain below why neither the competition nor the disintermediation effects would appear in the framework with two-part tariffs.

\footnotetext{
${ }^{28}$ We would obtain the same qualitative results in using a quadratic utility function defined by Vives (1985).
} 


\subsection{The competition effect}

To study the competition effect, we first describe the benchmark with $n$ manufacturers and then consider the entry of a new symmetric manufacturer.

\subsubsection{The benchmark}

Regardless of the number of varieties $m$ that the monopsonist multi-product distributor chooses to sell (i.e., $\forall m \in[1, \ldots, n]$ ), her final prices $p_{i}$ for the $m$ brand products are established by maximising her profit function:

$$
\pi^{D}=\sum_{i=1}^{m}\left(p_{i}-w_{i}\right) q_{i}\left(p_{1}, \ldots, p_{m}\right)
$$

with $q_{i}\left(p_{1}, \ldots, p_{m}\right)$ defined by Equation (??).

We obtain the following equilibrium prices:

$$
p_{i}\left(w_{i}\right)=\frac{v+w_{i}}{2}, \quad \forall i=1, \ldots, m
$$

Replacing (??) in $q_{i}\left(p_{1}, \ldots, p_{m}\right)$, we obtain the following quantity:

$q_{i}\left(w_{1}, \ldots, w_{m}\right)=\frac{1}{2 n(1-\beta) \gamma}\left[n(1-\beta) v-\gamma w_{i}+\beta \sum_{j=1}^{m} w_{j}\right]$ for the $m$ brand products. For any symmetric wholesale prices $\left(w_{i}=w_{j}=w\right)$, the distributor's profit is increasing in $m$; therefore, the distributor is in a strictly better position offering $m=n$ products on its shelves. ${ }^{29}$

Going backward to Stage 3 of the game, the manufacturers establish their wholesale price $w_{i}$ to maximise their profit; that is, $\pi_{i}=\left(w_{i}-c\right) q_{i}\left(w_{1}, \ldots, w_{n}\right)$, and thus:

$$
w_{i}(c)=\frac{n(1-\beta) v+(n-\beta) c}{2 n-\beta(n+1)}, \quad \forall i=1, \ldots, n .
$$

We determine the total demand on the input market absent fair trade as follows:

$$
Q^{n}(c)=\frac{(n-\beta)(v-c)}{2(2 n-\beta(n+1))} .
$$

\footnotetext{
${ }^{29}$ The distributor's profit is $\pi^{D}=\frac{m(v-w)^{2}}{4 \gamma}$, increasing in $m$.
} 
The harvest level (i.e., the supply) is $R$, and the demand that is defined by Equation (??) determines the spot price of the raw product explicitly in the following lemma.

Lemma 5. In a market with $n$ manufacturers that offer linear tariff contracts to the distributor, the equilibrium spot price is as follows:

$$
c_{3}^{*}(R)= \begin{cases}v-\frac{2(2 n-\beta(n+1)) R}{n-\beta} & \text { if } R \leq \dot{R}_{3}=\frac{(n-\beta) v}{2(2 n-\beta(n+1))} \\ 0 & \text { if } \dot{R}_{3}<R<R^{+} .\end{cases}
$$

Stronger competition induces an increase in the spot price. When $n$ increases, the competition among manufacturers increases, and the equilibrium wholesale price is lowered. In turn, the retailer lowers its retail price; this increases the total consumer demand. Through a feedback effect, demand also increases on the raw market and the spot price increases. Moreover, the equilibrium spot price $c_{3}^{*}(R)$ is more likely to be strictly positive when the maximum market size is high, the intermediary market is competitive and the products are closer substitutes.

\subsubsection{The entry of a new manufacturer}

We now analyse the entry of a new manufacturer. The distributor agrees to sell the entrant's product because its profit increases the number of brands that are offered to consumers. With the game identical to that in the previous subsection, we directly present the results. The equilibrium values are denoted by an index of " 3 ".

Lemma 6. In a market with $n+1$ manufacturers with linear tariff contracts between the manufacturers and the distributor, the equilibrium spot price is as follows:

$$
c_{3^{\prime}}^{*}(R)= \begin{cases}v-\frac{2[2(n+1)-\beta(n+2)] R}{n+1-\beta} & \text { if } R \leq \dot{R}_{3^{\prime}}=\frac{(n+1-\beta) v}{2[2(n+1)-\beta(n+2)]} \\ 0 & \text { if } \dot{R}_{3^{\prime}}<R<R^{+} .\end{cases}
$$


An analytical comparison with the benchmark case yields the following result.

Proposition 3. The entry of a new manufacturer intensifies competition and increases the spot price.

Proof. It is straightforward to show that $c_{3^{\prime}}^{*}(R) \geq c_{3}^{*}(R)$ for all $R$ and that $\dot{R}_{3^{\prime}} \geq \dot{R}_{3}$ for all $\beta \in[0,1[$.

When $c_{3}^{*}(R)>0$, the entry of a new manufacturer does not change either the wholesale price or the retail price. When $c_{3^{\prime}}^{*}(R)=0$ and when there are $n+1$ manufacturers, the wholesale and retail prices are lower than the prices in a market with $n$ manufacturers. The entry of a new manufacturer intensifies competition in the upstream market, in the input market, or in the downstream market through the relationships between the manufacturers and the distributor. This "competition" effect, which is not specific to fair trade, induces an increase in the spot price (that is, a snowball effect). Note that in the two-part tariff case, this competition effect would be entirely captured through the fixed fee and thus would not affect the total demand. Competition would not create any snowball effect.

\subsection{The disintermediation effect}

We now analyse the disintermediation process (i.e., the direct relationship between some farmers and the distributor through a Fairtrade organisation). The equilibrium values in this subsection are denoted by an index of "3". Details pertaining to the model resolution are given in Appendix ??.

We obtain the following result.

Lemma 7. In a market with a Fairtrade channel with linear tariff contracts between the $n$ manufacturers and the distributor, the distributor sells the $n$ brand products and the Fairtrade product 
when none of the products are close substitutes.

- In this case, the equilibrium GMP is

$$
G_{3}^{*}=\frac{(1+n) v(-1+\beta)\left((-2+\beta)^{2}+2 n^{3}(-1+\beta)+5 n^{2} \beta-n\left(-6+\beta+\beta^{2}\right)+\sqrt{Z}\right)}{-8(1+n)^{3}(2+n)+(1+n)^{2}(32+n(24+5 n)) \beta-2(1+n)(10+n(7+3 n)) \beta^{2}+(4+n(2+n)) \beta^{3}}
$$

$$
\begin{aligned}
\text { with } Z= & 4(1+n)^{4}(2+3 n)^{2}-4(1+n)^{3}(2+n)(4+n(13+7 n)) \beta \\
& +(1+n)^{2}\left(24+n\left(108+n\left(101+46 n+4 n^{2}\right)\right)\right) \beta^{2} \\
& -2(1+n)(4+n(21+n(19+10 n))) \beta^{3}+(1+n(6+n(5+2 n))) \beta^{4}
\end{aligned}
$$

- the equilibrium spot price is

$$
c_{3}^{f}(R)= \begin{cases}c_{03}^{f}(R)=v-\frac{2(n+1)(2-\beta) R}{n+2-\beta} & \text { when } R<\widehat{R}_{3}\left(G_{3}^{*}\right) \\ c_{13}^{f}\left(R, G_{3}^{*}\right)=\frac{(n+1)[(n+2-\beta) v-2(n+1)(2-\beta) R]-(2 n+2-\beta) G_{3}^{*}}{n(n+1-\beta)} & \text { when } \widehat{R}_{3}\left(G_{3}^{*}\right) \leq R \leq \check{R}_{3}\left(G_{3}^{*}\right) \\ 0 & \text { when } R>\check{R}_{3}\left(G_{3}^{*}\right)\end{cases}
$$

- and the equilibrium Fairtrade price is thus $P_{3}^{*}=\max \left\{G_{3}^{*}, c_{03}^{f}(R)\right\}$.

Proof. see Appendix ??.

When all of the products are strong substitutes, the competition is so intense between the $n$ brand products that the Fairtrade product cannot enter the market with a sufficiently high GMP to support the Fairtrade-certified farmers.

\subsection{Comparison}

We here compare the spot price that is obtained with a Fairtrade channel with the spot price in the benchmark case.

Proposition 4. Through competition and disintermediation effects, Fairtrade contracts tend to increase the spot price. A snowball effect arises in equilibrium when $R<\check{R}_{3}\left(G_{3}^{*}\right)$. 
Proof. See Appendix ??.

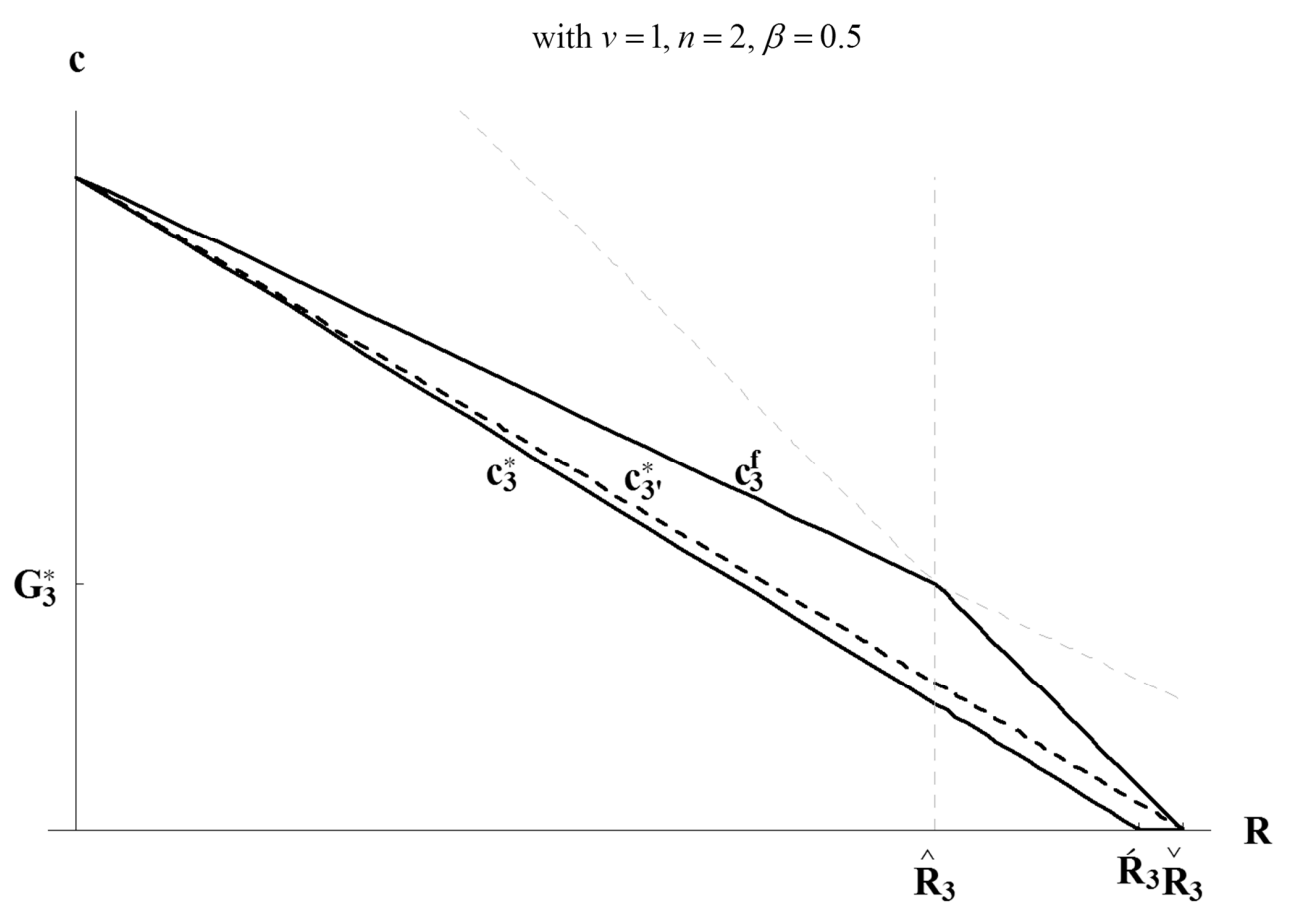

Figure 3: Competition and disintermediation effects

When the harvest is lower than $\check{R}_{3}$, all of the profits of the farmers are higher with than without the Fairtrade channel. Figure 3 illustrates the comparison of the equilibrium spot prices with and without Fairtrade, as previously given. We add the dashed line that represents the spot price only when the product $n+1$ is offered by a new manufacturer, $c_{3^{\prime}}^{*}$. The figure shows an initial snowball effect $\left[c_{3}^{*}-c_{3^{\prime}}^{*}\right]$, caused by the "competition" effect presented in Subsection ??. A second snowball effect $\left[c_{3^{\prime}}^{*}-c_{03}^{f}\right]$ that is known as the "disintermediation" effect appears.

With a Fairtrade channel, the wholesale price that is paid by the distributor for the Fairtrade product to the Fairtrade-certified farmers when $R<\widehat{R}_{3}, P_{3}^{*}=c_{03}^{f}$ is lower than the wholesale price that is paid to the manufacturers. Thus, the final price of the Fairtrade product is lower than 
the final price of each brand product. ${ }^{30}$ This disintermediation effect cannot be highlighted when the manufacturers offer efficient two-part tariff contracts. Indeed, with two-part tariffs, the unit price offered by the manufacturers are equal to the spot price; whenever the GMP is higher than the spot price, the introduction of a Fairtrade creates a double marginalization, which tends to reduce the snowball effect (a direct negative "GMP" effect). In contrast, when the manufacturers offer a linear tariff to the distributor, the introduction of a Fairtrade channel naturally creates a disintermediation effect by eliminating the double-margin effect. This disintermediation increases the demand for the Fairtrade product, reduces the supply in the spot market, and thus the spot price increases. In this case, the spot price, $c_{03}^{f}$, is increasing in $\beta$ as expected but is decreasing in $n$. A larger $n$ is associated with a weaker initial double marginalisation effect. Therefore, the effect of disintermediation is smaller when $n$ is larger.

When the level of the harvest is higher $\left(R>\widehat{R}_{3}\right)$, these two positive effects are counterbalanced by the direct negative "GMP" effect. Indeed, the final price of the Fairtrade product becomes higher than the brand final price, and the demand for the Fairtrade product decreases. This decrease induces an increase in the supply in the spot market and thus a decrease in the spot price. However, the two positive effects are not entirely counterbalanced by the negative "GMP" effect. A snowball effect still occurs. When $\check{R}_{3}\left(G_{3}^{*}\right)<R<R^{+}$, the spot price decreases to zero with or without Fairtrade.

\footnotetext{
${ }^{30}$ It might appear unrealistic that the Fairtrade products are less expensive than the other varieties for the distributor and for consumers. However, we do not consider the vertical differentiation between the Fairtrade good and the brand products here, nor do we consider that some consumers are willing to pay a premium for a product that meets Fairtrade criteria.
} 


\section{Conclusion}

This article provides arguments that countervail the oversupply criticism that is addressed regarding Fairtrade. This criticism is that the high prices (GMP) that are offered to farmers by Fairtrade organisations may induce them to expand their production and thus possibly reduce spot prices. Nevertheless, some Fairtrade organisations claim that by paying a higher price for a part of the harvest, there is a positive snowball effect on the spot price that is paid for the remainder of the production. Our article eliminates by assumption the oversupply effect by excluding decisionmaking farmers. However, we highlight several mechanisms that are linked to the demand or market structure and that may explain the snowball effect. We show that after the introduction of a Fairtrade channel and despite the direct negative effect of the GMP offered by the Fairtrade system, a snowball effect arises in equilibrium as a result of (i) a variety effect, (ii) a premium effect, (iii) a competition effect, and/or (iv) a disintermediation effect. Therefore, as the oversupply effect is neglected, all farmers benefit from the introduction of the Fairtrade product through the spot market when the harvest is not excessively strong. A consideration of both the oversupply and snowball effects that are highlighted in our model is outside of the scope of this article but clearly appears to be a challenging issue for further research.

Each mechanism that generates the snowball effect could be applied to other market situations. For instance, the premium effect can be studied when a product holds a specific attribute that is valued by consumers. In addition, the competition and disintermediation effects that are underlined by our model could also be applied to agricultural marketing cooperatives or to farmers who sell their products using direct or online markets. Our paper has shown that all of the four highlighted sources of the snowball effect could be relevant when considering the introduction of a Fairtrade channel. Moreover, we have proven that, provided that the harvest level is not too strong, each of 
these sources is sufficient to compensate for the Fairtrade-specific negative effect of the GMP.

\section{References}

Allaz, B. and Vila, J.-L. (1993). Cournot Competition, Forward Markets and Efficiency. Journal of Economic Theory 59: 1-16.

Bontems, P. and Bouamra-Mechemache, Z. (2004). Predatory Accomodation in vertical contracting with externalities. Working Paper INRA Toulouse.

Booth, P. M. and Whetstone, L. (2007). Half a Cheer for Fair Trade. Economic Affairs 27: 29-36.

Bowen, B. (2001). Let's go fair! In EFTA, Fair Trade Yearbook 2001, www.eftafairtrade.org.

Fraser, R.W. (1988). A Method for Evaluating Supply Response to Price Underwriting. Australian Journal of Agricultural Economics 32: 22-36.

FLO. (2008). Fairtrade Leading the Way. 2008 Annual Report, Fairtrade Labelling Organizations International. Available at http:// www.fairtrade.net.

Giovannucci, D. (2003). Emerging issues in the marketing and trade of organic products. In Organic Agriculture: Sustainability, Markets, and Policies. OECD, Paris.

Griffiths, P. (2010). Lack of Rigour in Defending Fairtrade. Economic Affairs 30: 45-49.

Henderson, D. (2008). Fair Trade is Counterproductive and Unfair. Economic Affairs 28: 62-64.

Höffler, F. (2008). On the consistent use of linear demand systems when not all varieties are available. Economics Bulletin 4: 1-5. 
Hua, X. (2007). The Right of First Offer. Working Paper of Hong Kong University of Science and Technology.

Loureiro, M. and Lotade, J. (2005). Do Fair Trade and Eco-labels in Coffee Wake up the Consumer Conscience? Ecological Economics 53: 129-38.

Love, H.A. and Burton, D.M. (1999). A Strategic Rationale for Captive Supplies. Journal of Agricultural and Resource Economics 24: 1-18.

Mahé, T. (2010). Are Stated Preferences Confirmed by Purchasing Behaviours? The Case of Fair Trade-Certified Bananas in Switzerland. Journal of Business Ethics 92: 301-315.

Mann, S. (2008). Analysing fair trade in economic terms. Journal of Socio-Economics 37: 20342042.

Milford, A. (2004). Coffee, co-operatives and competition : the impact of Fair Trade. Chr. Michelsen Institute.

McCorriston, S. (2002). Why should imperfect competition matter for agricultural economists? European Journal of Agricultural Economics 29: 349-371.

Moore, G. (2004). The Fair Trade movement: parameters, issues and future research. Journal of Business Ethics 53: 73-86.

Motta, M. (2004). Competition Policy: Theory and Practice. Cambridge University Press.

Oxford Management Policy. (2000). Overview, Impact, Challenges Study to Infrom DFID's support to Fair Trade. Oxford Policy Management report.

Oxfam. (2002). Une tasse de café au goût d'injustice. Oxfam International. 
Potts, J. (2007). Alternative trade initiatives and income predictability: Theory and evidence from the coffee sector. Winnipeg, Manitoba, Canada: International Institute for Sustainable Development.

Poret, S. (2010). Mainstreaming Fair Trade: A Discussion Through the Lipton Tea Case. In Crifo, P. and Ponssard, J-P. (Eds), Corporate social responsibility: from compliance to opportunity? Editions de 1'Ecole Polytechnique, Palaiseau.

Poret, S. and Chambolle, C. (2007). Fair Trade Labeling: Inside or Outside Supermarkets? Journal of Agricultural \& Food Industrial Organization 5(1).

Raynolds, L. T. (2000). Re-Embedding Global Agriculture: The International Organic and Fair Trade Movements. Agriculture and Human Values 17: 297-309.

Reinstein, D. and Song, J. (2012).Efficient Consumer Altruism and Fair Trade. Journal of Economics \& Management Strategy, 21: 213Ü241.

Renard, M.-C. (2003). Fair Trade: quality, market and conventions. Journal of Rural Studies 19: 87-96.

Renard, M.-C. (2005). Quality certification, regulation and power in Fair Trade. Journal of Rural Studies 21: 419-431.

Shubik, M. and Levitan, R. (1980). Market Structure and Behavior. Harvard University Press, Cambridge, Massachusetts.

Sidwell, M. (2008). Unfair Trade. Adam Smith Institute: London.

Smith, A. M. (2010). Lack of rigour in defending Fairtrade: Some important clarifications of a distorting account - a reply to Peter Griffiths. Economic Affairs 30: 50-53. 
Smith, A. M. (2009). Evaluating the Criticisms of Fair Trade: How strong is the argument that consumers and businesses should abandon Fair Trade as a means to socialise their economic decisions? Economic Affairs 19: 29-36.

UNCTAD. (2008). Cocoa Study: Industry Structures and Competition. New York and Geneva.

Vives, X. (1985). On the efficiency of Bertrand and Cournot equilibria with product differentiation. Journal of Economic Theory 36: 166-75.

Vives, X. (2001). Oligopoly Pricing Old Ideas and New Tools. MIT Press, Cambridge, MA.

Xia, T., and Sexton, R.J. (2004). The competititive implications of Top-of-Market and Related Contract-Pricing Clauses. American Journal of Agricultural Economics 86: 124-138.

\section{A Appendices}

\section{A.1 Two-part Tariff Contracts: the variety effect}

\section{A.1.1 Absent fair trade}

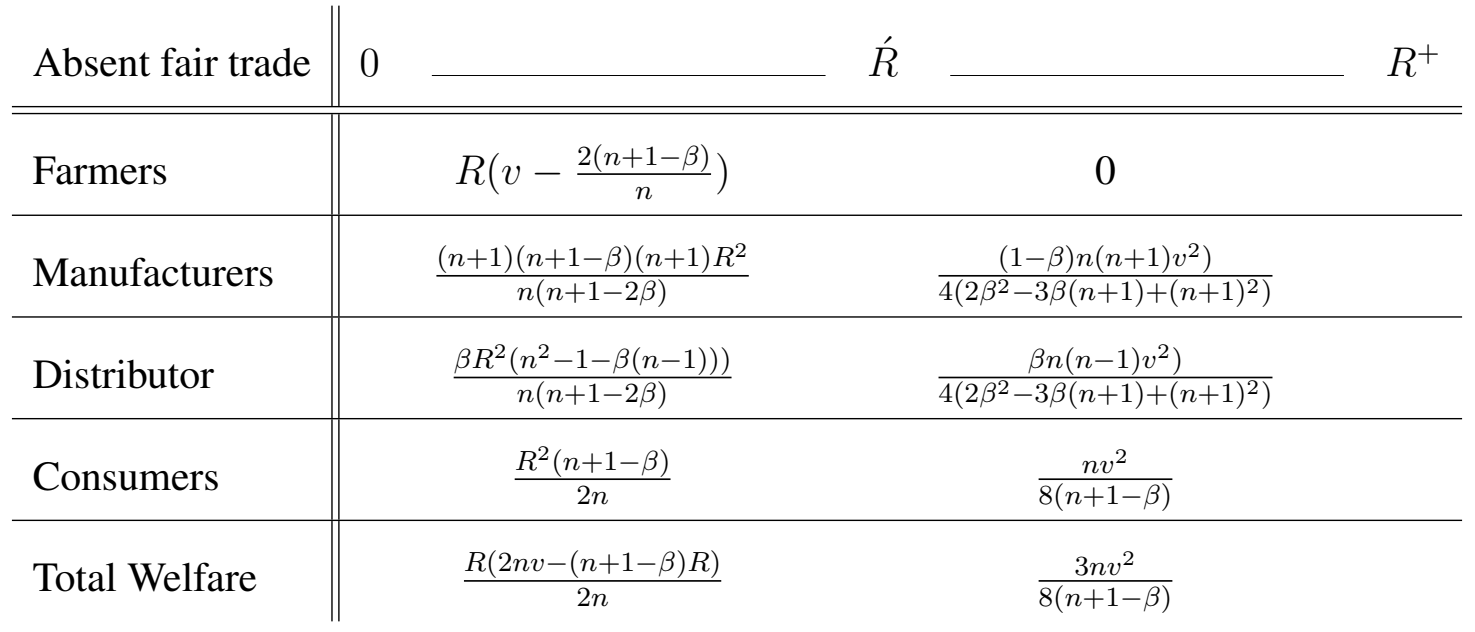




\section{A.1.2 With Fairtrade}

In the last stage, equilibrium prices are:

$$
\left\{\begin{array}{l}
p_{i}=\frac{v+w_{i}}{2} \quad \forall i=1, \ldots, n \\
p^{f}=\frac{v+P}{2}
\end{array}\right.
$$

In the third stage, manufacturer's profit maximization leads to $w_{i}=c$ and

$$
T_{i}^{n, f}=\left(p_{i}-c\right)\left(Q^{n, f}-q^{n, f}-Q^{n-1, f}+q^{n-1, f}\right)+\left(p^{f}-P\right)\left(q^{n, f}-q^{n-1, f}\right),
$$

where $Q^{n, f}$ denote the total quantity of products sold when there are $n$ brands and a Fairtrade product on the market and $q^{n, f}$ denote the Fairtrade product quantity when there are also $n$ brands offered by the distributor. We obtain:

$$
T_{k}^{n, f}=\frac{(v(n+1)+\beta(P-(n+1) v)-c(1+n(1-\beta)))^{2}}{4(1-\beta)(1+n)^{2}(n+1-\beta)}
$$

This equilibrium tariff is clearly increasing with $P$. We check that the distributor never has any incentive to sell only the Fairtrade product. Total demand of raw product on the input market is then

$$
Q^{n, f}=\frac{v(n+1)-P-c n}{2(n+1)} .
$$

The equality between supply and demand determines the following results. Note also that when $P \leq v-2 \beta R$, the demand for Fairtrade product is strictly positive and amounts to: $q^{n, f}(c, P)$.

To sum-up, on a market with a Fairtrade channel, the sub-game equilibrium spot price for raw products $c_{1}^{f}$ depends on the Fairtrade price $P$ and the level of the harvest.

Let us denote by $\bar{R}_{1}(G)$ the maximum level of the harvest such that the demand for the Fairtrade product is positive $q^{n, f}\left(c\left(G, \bar{R}_{1}\right), \bar{R}_{1}\right)=0$, which rewrites as $\bar{R}_{1}(G)=\frac{v-G}{2 \beta}$.

(i). If $G<v(1-\beta)$ 
- If $R \leq \widehat{R}_{1}(G)$, the distributor sells a quantity $q^{n, f}\left(c_{01}^{f}, c_{01}^{f}\right)=\frac{R}{n+1}$ of Fairtrade product and the $n$ brands, and the spot market price is $c_{01}^{f}=v-2 R$.

- $\widehat{R}_{1}(G)<R \leq \check{R}_{1}(G)$, the distributor sells a quantity $q^{n, f}\left(c_{11}^{f}, G\right)=\frac{v-2 \beta R-G}{2(1-\beta)(n+1)}$ of Fairtrade product and the $n$ brands, and the spot price is $c_{11}^{f}=\frac{(n+1)(v-2 R)-G}{n}$

- If $\check{R}_{1}(G)<R \leq R^{+}$, the distributor sells a quantity $q^{n, f}(0, G)=\frac{(n+1)(1-\beta) v-G(n+1-\beta)}{2(1-\beta)(n+1)^{2}}$ of Fairtrade product and all the brand products, and the spot price is $c^{f}=0$.

In this case, maximizing the Fairtrade certified farmers' expected profit, Equation (??), with respect to $G$, we obtain a unique solution $G_{1}^{*}$ and we easily check that $\bar{R}_{1}\left(G_{1}^{*}\right)>R^{+}$for all $\beta \in[0,1]$

(ii). If $v(1-\beta) \leq G \leq \frac{v(1-\beta)}{1-\beta /(n+1)}$

- If $R \leq \widehat{R}_{1}(G)$, the distributor sells a quantity $q^{n, f}\left(c_{01}^{f}, c_{01}^{f}\right)=\frac{R}{n+1}$ of Fairtrade product and the $n$ brands, and the spot market price is $c_{01}^{f}=v-2 R$.

- $\widehat{R}_{1}(G)<R \leq \check{R}_{1}(G)$, the distributor sells a quantity $q^{n, f}\left(c_{11}^{f}, G\right)=\frac{v-2 \beta R-G}{2(1-\beta)(n+1)}$ of Fairtrade product and the $n$ brands;

- If $\check{R}_{1}(G)<R \leq \bar{R}_{1}(G)$, the distributor sells a quantity $q^{n, f}(0, G)=\frac{(n+1)(1-\beta) v-G(n+1-\beta)}{2(1-\beta)(n+1)^{2}}$ of Fairtrade product and all the brand products, and the spot price is $c_{1}^{f}=0$.

- If $\bar{R}_{1}(G)<R \leq R^{+}$, the distributor does not sell the Fairtrade product but only the $n$ brands and the spot price is $c_{1}^{*}$.

In that case, the Fairtrade organization maximizes:

$$
\begin{aligned}
\mathbb{E}\left(\pi^{f}(G)^{i i}\right) & =\int_{0}^{\widehat{R}_{1}(G)} c_{01}^{f}(R) q^{n, f}\left(c_{01}^{f}, c_{01}^{f}\right) d R+\int_{\widehat{R}_{1}(G)}^{\check{R}_{1}(G)} G q^{n, f}\left(c_{11}^{f}, G\right) d R \\
& +\int_{\check{R}_{1}(G)}^{\bar{R}_{1}(G)} G q^{n, f}(0, G) d R
\end{aligned}
$$


where $q^{n, f}\left(c_{01}^{f}, c_{01}^{f}\right)=\frac{R}{n+1}, q^{n, f}\left(c_{11}^{f}, G\right)=\frac{v-2 \beta R-G}{2(1-\beta)(n+1)}$ and $q^{n, f}(0, G)=\frac{(1-\beta)(n+1) v-G(n+1-\beta)}{2(1-\beta)(n+1)^{2}}$.

The two solutions never respect the initial assumption (ii).

(iii). If $\frac{v(1-\beta)}{1-\beta /(n+1)} \leq G$

- If $R \leq \widehat{R}_{1}(G)$, the distributor sells a quantity $q^{n, f}\left(c_{01}^{f}, c_{01}^{f}\right)=\frac{R}{n+1}$ of Fairtrade product and the $n$ brands, and the spot market price is $c_{01}^{f}=v-2 R$.

- $\widehat{R}_{1}(G)<R \leq \bar{R}_{1}(G)$, the distributor sells a quantity $q^{n, f}\left(c_{11}^{f}, G\right)=\frac{v-2 \beta R-G}{2(1-\beta)(n+1)}$ of Fairtrade product and the $n$ brands, and the spot price is $c_{11}^{f}=\frac{(n+1)(v-2 R)-G}{n}$

- If $\bar{R}_{1}(G)<R<R^{+}$, the distributor does not sell the Fairtrade product but only the $n$ brands and the spot price is $c_{1}^{*}$.

In that case, the Fairtrade organization maximizes:

$$
\mathbb{E}\left(\pi^{f}(G)^{i i i}\right)=\int_{0}^{\widehat{R}_{1}(G)} c_{01}^{f}(R) q^{n, f}\left(c_{01}^{f}, c_{01}^{f}\right) d R+\int_{\widehat{R}_{1}(G)}^{\bar{R}_{1}(G)} G q^{n, f}\left(c_{11}^{f}, G\right) d R
$$

The optimum is $G=\frac{v(1-\beta)}{3-\beta}$ which does not respect the initial condition (iii).

The equilibrium spot price with the Fairtrade system is thus uniquely defined by (??).

To sum-up, we obtain:

\begin{tabular}{|c|c|}
\hline With fair trade & 0 \\
\hline Farmers & $R(v-2 R)$ \\
\hline Manufacturers & $\frac{(1-\beta) n R^{2}}{n+1-\beta}$ \\
\hline Distributor & $\frac{(n \beta+1-\beta) R^{2}}{n+1-\beta}$ \\
\hline Consumers & $\frac{R^{2}}{2}$ \\
\hline Total Welfare & $\frac{R(2 v-R)}{2}$ \\
\hline
\end{tabular}




\begin{tabular}{|c|c|c|}
\hline With fair trade & $\widehat{R}_{1}$ & \\
\hline Farmers & & $\frac{\left.2 v H\left(4(n+1)^{3}+\beta^{2} n(4+n(n+2))-\beta(4+n(4+n(8+5 n)))\right) R-v L^{2}\right)}{\left(2(1-\beta n)(H)^{2}\right)}-\frac{2(1+n(1-\beta)) R^{2}}{(1-\beta) n}$ \\
\hline Manufacturers & & $\frac{L^{2}-2(n(1-\beta)+1) H R}{4(1-\beta)(n+1-\beta) n H^{2}}$ \\
\hline Distributor & & $\frac{4 \beta(n-1)(1+(1-\beta) n) H^{2} R^{2}+4 \beta(n-1) L H R v-v^{2}(n-\beta) L^{2}}{4(n+1-\beta)(1-\beta) n H^{2}}$ \\
\hline Consumers & & $\frac{4(1+n(1-\beta) n) H^{2} R^{2}-4 L H R v}{8(1-\beta) n H^{2}}$ \\
\hline Total Welfare & $\underline{-4(n}$ & $\frac{+(1-\beta) n) H^{2} R^{2}+4 H\left(2(n+1)^{2}(1+4 n)+2 \beta^{2} n(4+n(2+n))-\beta(2+n(14+n(19+10 n))) R v-L 2 v^{2}\right.}{8(1-\beta) n H^{2}}$ \\
\hline
\end{tabular}

where $H=4(n+1)^{2}-\beta(4+n(2+n)), L=2(n+1)^{2}-\beta(2-n(2+n))$.

\begin{tabular}{|c|c|}
\hline With fair trade & $\check{R}_{1}$ \\
\hline Farmers & $\frac{(1-\beta)(n+1)\left(2(n+1)^{2}-\beta\left(2+n^{2}\right)\right) v^{2}}{H^{2}}$ \\
\hline Manufacturers & $\frac{(1-\beta) n H^{2} v^{2}}{4(n+1-\beta) H^{2}}$ \\
\hline Distributor & $\frac{4(n+1)^{4}+\beta^{3}(n-1)\left(2+n^{2}\right) 2-4 \beta(n+1)^{2}\left(3+2 n-2 n^{2}-4 n^{3}\right)+\beta^{2}\left(12(n+1)-8 n^{3}\left(1+n^{2}\right)-7 n^{4}\right) v^{2}}{4(N+1-\beta) H^{2}}$ \\
\hline Consumers & $\frac{\left.4(n+1)^{3}(1+4 n)+\beta^{2}\left(2+n^{2}\right)^{2}-4 \beta\left(2+7 n+7 n^{2}+4 n^{3}+2 n^{4}\right)\right) v^{2}}{8\left(H^{2}\right)}$ \\
\hline Total Welfare & $\frac{\left.\left.4(n+1)^{3}(7+12 n)+\beta^{2}\left(28+16 n+20 n^{2}+8 n^{3}+3 n^{4}\right)-4 \beta\left(14+37 n+35 n^{2}+18 n^{3}+6 n^{4}\right)\right) v^{2}\right)}{8 H^{2}}$ \\
\hline
\end{tabular}

\section{A.1.3 Proof of Proposition ??}

The equilibrium spot price absent fair trade being (??), it is straightforward to show that

$$
\begin{array}{lll}
c_{01}^{f}(R)>c_{1}^{*}(R) & \forall R ; \\
c_{11}^{f}(R)>c_{1}^{*}(R) & \forall R<\check{R}_{1} ; \\
c_{1}^{f}(R) \quad=c_{1}^{*}(R)=0 & \forall \check{R}_{1}<R<R^{+}
\end{array}
$$




\section{A.2 Premium Effect}

\section{A.2.1 With fair trade}

The resolution of the game is similar to the previous one. We go straight to the first stage where the Fairtrade organization chooses the level of the premium which maximizes the expected utility of Fairtrade-certified farmers. The quantity of Fairtrade good is equal to

$$
q^{f}(c(G, R), G)=\frac{v^{f}-G-2 \beta R}{2(1-\beta)(n+1)} .
$$

We define $\bar{R}_{2}=\frac{v^{f}-G}{2 \beta}$, the maximum level of the harvest such that there is a positive quantity of Fairtrade product sold.

Let $c_{02}^{f}=\frac{n v+v^{f}-2(n+1) R}{n+1}$ and $\widehat{R}_{2}(G)=\frac{n v+v^{f}-(n+1) G}{2(n+1)}$ the level of the harvest such that $G<c_{02}^{f}$ if and only if $R<\widehat{R}_{2}(G)$. In case where $P=\max \left\{c_{02}^{f}, G\right\}=c_{02}^{f}$, the quantity of Fairtrade product sold is

$$
q^{f}\left(c_{02}^{f}, c_{02}^{f}\right)=\frac{2(1-\beta)(n+1) R+n\left(v^{f}-v\right)}{2(1-\beta)(n+1)^{2}}
$$

Let finally $\check{R}_{2}(G)$ define the level of the harvest such that if $R>\check{R}_{2}(G), c_{2}^{f}=0$ and then the Fairtrade demand is

$$
q^{f}(0, G)=\frac{v^{f}(n+1)-\beta\left(n v+v^{f}\right)-G(n+1-\beta)}{2(1-\beta)(n+1)^{2}}
$$

(i). If $G<v^{f}-v$,

- if $R \leq \widehat{R}_{2}(G)$, the distributor sells a quantity $q^{f}\left(c_{02}^{f}, c_{02}^{f}\right)$ of Fairtrade product and the $n$ brands, and the spot price is $c_{02}^{f}$,

- if $\widehat{R}_{2}(G)<R \leq R^{+}$, the distributor sells a quantity $q^{f}(c(G, R), G)$ of Fairtrade product and the $n$ brands, and the spot market price is $c_{12}^{f}(R)=\frac{n v+v^{f}-2(n+1) R-G}{n}$. 
Maximizing

$$
\mathbb{E}\left(\pi^{f}(G)^{i}\right)=\int_{0}^{\widehat{R}_{2}(G)} c_{02}^{f}(G) q^{f}\left(c_{02}^{f}, c_{02}^{f}\right) d R+\int_{\widehat{R}_{2}(G)}^{R^{+}} G q^{f}\left(c_{12}^{f}(R), G\right) d R
$$

with respect to $G$, we obtain a unique solution $G_{2}^{* i}=\frac{2(n+1) v^{f}-\beta\left(v(1+2 n)+v^{f}\right)}{(4-\beta)(n+1)}$ and we easily check that $G_{2}^{* i}<v^{f}-v$ for $v^{f}>\widehat{v}^{f}=\frac{((4(n+1)-\beta(3 n+2)) v}{2+(2-\beta) n}$.

(ii). If $v^{f}-v \leq G \leq v^{f}-\beta v$,

- if $R \leq \widehat{R}_{2}(G)$, the distributor sells a quantity $q^{f}\left(c_{02}^{f}, c_{02}^{f}\right)$ of Fairtrade product and the $n$ brands, and the spot price is $c_{02}^{f}$,

- if $\widehat{R}_{2}(G)<R \leq \check{R}_{2}(G)$, the distributor sells a quantity $q^{f}\left(c_{12}^{f}, G\right)$ of Fairtrade product and the $n$ brands, and the spot price is $c_{12}^{f}(R)$,

- if $\check{R}_{2}(G)<R \leq R^{+}$, the distributor sells a quantity $q^{f}(0, G)$ of Fairtrade product and all the brand products, and the spot market price is 0 .

In that case, the Fairtrade organization maximizes:

$$
\begin{aligned}
\mathbb{E}\left(\pi^{f}(G)^{i i}\right) & =\int_{0}^{\widehat{R}_{2}(G)} c_{02}^{f} q^{f}\left(c_{02}^{f}, c_{02}^{f}\right) d R+\int_{\widehat{R}_{2}(G)}^{\check{R}_{2}} G q^{f}\left(c_{12}^{f}(R), G\right) d R \\
& +\int_{\check{R}_{2}(G)}^{R^{+}} G q^{f}(0, G) d R
\end{aligned}
$$

There is only one maximum

$$
G_{2}^{* i i}=\frac{(n+1-\beta)(n+3) v^{f}-\left(2(n+1)+\beta\left(n^{2}+n-2\right)\right) v+\frac{1}{2} \sqrt{Y}}{4(n+1)^{2}-\beta(4+n(2+n))}
$$

where $Y=4\left(\left(2(n+1)+\beta\left(n^{2}+n-2\right)\right) v-(n+1-\beta)(3+n) v^{f}\right)^{2}+8(\beta(4+n(2+n))-$ $\left.4(n+1)^{2}\right)\left(v^{f}-v\right)\left((n+1) v^{f}-\beta\left(n v+v^{f}\right)\right)$, and this solution meets the initial condition (ii) only if $v^{f} \in\left[v, \widehat{v}^{f}\right]$.

(iii). If $v^{f}-\beta v \leq G \leq v^{f}-v \frac{\beta n}{n+1-\beta}$, 
- if $R \leq \widehat{R}_{2}(G)$, the distributor sells a quantity $q^{f}\left(c_{02}^{f}, c_{02}^{f}\right)$ of Fairtrade product and the $n$ brands, and the spot price is $c_{02}^{f}$,

- if $\widehat{R}_{2}(G)<R \leq \check{R}_{2}(G)$, the distributor sells a quantity $q^{f}\left(c_{12}^{f}, G\right)$ of Fairtrade product and the $n$ brands, and the spot price is $c_{12}^{f}(R)$,

- if $\check{R}_{2}(G)<R \leq \bar{R}_{2}(G)$ the distributor sells a quantity $q^{f}(0, G)$ of Fairtrade product and all the brand products, and the spot price is 0 ,

- if $\bar{R}_{2}(G)<R \leq R^{+}$, the distributor does not sell the Fairtrade product but only the $n$ brands and the spot price is $c_{2}^{*}$.

In that case, the Fairtrade organization maximizes:

$$
\begin{aligned}
\mathbb{E}\left(\pi^{f}(G)^{i i i}\right) & =\int_{0}^{\widehat{R}_{2}(G)} c_{02}^{f} q^{f}\left(c_{02}^{f}, c_{02}^{f}\right) d R+\int_{\widehat{R}_{2}(G)}^{\check{R}_{2}} G q^{f}\left(c_{12}^{f}(R), G\right) d R \\
& +\int_{\check{R}_{2}(G)}^{R^{+}} G q^{f}(0, G) d R
\end{aligned}
$$

The optimum never meets the initial condition (iii).

(iv). If $v^{f}-v \frac{\beta n}{n+1-\beta} \leq G$,

- if $R \leq \widehat{R}_{2}(G)$, the distributor sells a quantity $q^{f}\left(c_{02}^{f}, c_{02}^{f}\right)$ of Fairtrade product and the $n$ brands, and the spot price is $c_{02}^{f}$,

- if $\widehat{R}_{2}(G)<R \leq \bar{R}_{2}(G)$, the distributor sells a quantity $q^{f}\left(c_{12}^{f}, G\right)$ of Fairtrade product and the $n$ brands, and the spot price is $c_{12}^{f}(R)$,

- if $\bar{R}_{2}<R \leq R^{+}$, the distributor does not sell the Fairtrade product but only the $n$ brands and the spot price is $c_{2}^{*}$.

In that case, the Fairtrade organization maximizes:

$$
\mathbb{E}\left(\pi^{f}(G)^{i v}\right)=\int_{0}^{\widehat{R}_{2}(G)} c_{02}^{f} q^{f}\left(c_{02}^{f}, c_{02}^{f}\right) d R+\int_{\widehat{R}_{2}(G)}^{\bar{R}_{2}(G)} G q^{f}\left(c_{12}^{f}(R), G\right) d R
$$


Again, the optimum never meets the initial condition (iv).

Synthesizing:

$$
G_{2}^{*}= \begin{cases}G_{2}^{* i i}, & \text { if } v^{f} \in\left[v, \widehat{v}^{f}\right] \\ G_{2}^{* i}, & \text { if } v^{f}>\widehat{v}^{f}\end{cases}
$$

\section{A.2.2 Comparison of spot prices}

Comparing $c_{2}^{f}$ with $c_{2}^{*}$ we obtain a threshold of harvest

$$
R_{2}^{S}=\frac{\left(2(n+1)+\beta\left(n^{2}+n-2\right)\right) v+v^{f}\left(1-\beta+(4-\beta) n+(3-\beta) n^{2}\right)+\frac{1}{2} \sqrt{K}}{8(n+1)^{2}-2 \beta(4+n(2+n))}
$$

where $K=4\left(\left(2(n+1)-\beta\left(2-n-n^{2}\right)\right) v-(n+1-\beta)(3+n) v^{f}\right)^{2}+8\left(v^{f}-v\right)\left(v^{f}(n+1)-\right.$ $\left.\beta\left(n v+v^{f}\right)\right)\left(4(n+1)^{2}-\beta(4+n(2+n))\right)$ such that $c_{12}^{f}(R)<c_{2}^{*}$ when $R>R_{2}^{S}$. We easily prove that $R_{2}^{S}<R^{+}$if and only if $\beta<\frac{2(n+1)\left(v^{f}-2 v\right)}{n v^{f}-(2+3 n) v}$.

\section{A.3 The disintermediation effect}

\section{A.3.1 Proof of Lemma ??}

Resolution of the last stages of the game

In Stage 4, the distributor maximizes its profit by choosing the retail prices of all products:

$$
\max _{p_{1}, \ldots, p_{m}, p^{f}} \pi^{D}=\sum_{i=1}^{m}\left(p_{i}-w_{i}\right) q_{i}\left(p_{1}, \ldots, p_{m}, p^{f}\right)+\left(p^{f}-P\right) q^{f}\left(p_{1}, \ldots, p_{m}, p^{f}\right) .
$$

with $q_{i}\left(p_{1}, \ldots, p_{n}, p^{f}\right)$, the quantity sold by the brand $i$ when there is a Fairtrade channel, and $q^{f}\left(p_{1}, \ldots, p_{n}, p^{f}\right)$, the quantity of Fairtrade product sold, defined by Equation (??) when $v^{f}=v$. Solutions are

$$
p^{f}(P)=\frac{v+P}{2} \quad \text { and } \quad p_{i}\left(w_{i}\right)=\frac{v+w_{i}}{2} \quad \forall i=1, \ldots, m
$$

As its profit is increasing in $m$, the distributor chooses to sell all the brand varieties, that is, $m=n$. 
Replacing (??) into the individual quantities, the $n$ brand manufacturers set their wholesale price maximizing their individual profit and considering the level of Fairtrade price $P$ as given:

$$
\max _{w_{i}} \pi_{i}=\left(w_{i}-c^{f}\right) q_{i}\left(w_{1}, \ldots, w_{n}, P\right)
$$

We then obtain that each manufacturer offers a wholesale price to the distributor equal to $w\left(c^{f}, P\right)=\min \left\{\frac{(1-\beta)(n+1) v+\beta P+(n+1-\beta) c^{f}}{(2-\beta)(n+1)}, \frac{(n+1)(1-\beta) v+\beta P}{n-n \beta+1}\right\}$, since the spot market exists only if $c \leq \bar{c}(P)=\frac{(1-\beta)(n+1) v+\beta P}{n+1-n \beta}$, and the total demand is equal to $Q^{n, f}=\frac{v}{2}-\frac{n w+P}{2(n+1)}$.

In Stage 2, supply $\left(R-q^{f}(c, P)\right)$ and demand $\left(n q_{i}(c, P)\right)$ determine the spot price which depends on the Fairtrade price.

(i). If $P<v-2 \beta R$, all the products are sold and the spot price is:

$$
c_{3}^{f}(R, P)=\frac{(n+1)(n+2-\beta) v-(2(n+1)-\beta) P-2(n+1)^{2}(2-\beta) R}{n(n+1-\beta)} \text { and } \pi^{D f}(R, P)=R^{2}+\frac{(v-P-2 R)^{2}}{4 n(1-\beta)} .
$$

(ii). If $P \geq v-2 \beta R$, the distributor sells only the $n$ brand products.

\section{Fairtrade certifier's choice}

In Stage 0, the Fairtrade certifier maximizes the expected profit of farmers producing the Fairtrade good by setting the GMP.

We first define the spot price when the Fairtrade product is paid at the same level as the brands, $c_{03}^{f}$, which is uniquely defined by the following equality:

$$
\begin{aligned}
R-q^{f}\left(c_{03}^{f}, c_{03}^{f}\right) & =n q_{k}\left(c_{03}^{f}, c_{03}^{f}\right) \\
c_{03}^{f}(R) & =v-\frac{2(n+1)(2-\beta) R}{n+2-\beta} .
\end{aligned}
$$

Let $c_{13}^{f}(R, G)$ be defined as the spot price when $G>c_{03}^{f}$ :

$$
\begin{aligned}
R-q^{n}\left(c_{13}^{f}, G\right) & =n q_{k}\left(c_{13}^{f}, G\right) \\
c_{13}^{f}(R, G) & =\frac{(n+1)[v(n+2-\beta)-2(n+1)(2-\beta) R]-(2 n+2-\beta) G}{n(n+1-\beta)} .
\end{aligned}
$$


We obtain that $c_{13}^{f}(R, G) \geq 0$ when $R \leq \frac{(n+1)(n+2-\beta) v-(2 n+2-\beta) G}{2(n+1)^{2}(2-\beta)}=\check{R}_{3}(G)<R^{+}$.

In that case, the quantity of Fairtrade product is equal to $q^{f}\left(c_{13}^{f}, G\right)$, which is higher than or equal to zero when $R \leq \frac{v-G}{2 \beta}=\bar{R}_{3}(G)$.

Let $\widehat{R}_{3}(G)$ denote the harvest threshold such that if $R<\widehat{R}_{3}(G), G<c_{03}^{f}(R, G)$. It is defined as $\widehat{R}_{3}(G)=q^{f}(G, G)+n q_{k}(G, G)=\frac{(v-G)(n+2-\beta)}{2(n+1)(2-\beta)}$ with $\widehat{R}_{3}(G)<\bar{R}_{3}(G)$ and $\widehat{R}_{3}(G)<\check{R}_{3}(G)$.

The Fairtrade organization program is $\max _{G} \mathbb{E}\left(\pi^{f}(G)\right)$. The expected profit of Fairtrade farmers depends on the level of $G$. We study three cases.

(i). If $G \leq v(1-\beta)$, that is, $\bar{R}_{3}(G) \geq R^{+}$,

- if $R \leq \widehat{R}_{3}$, the distributor sells the Fairtrade product in quantity $q^{f}\left(c_{0}^{f}, c_{0}^{f}\right)=\frac{(2 n+2-\beta) R}{(n+1)(n+2-\beta)}$ and the $n$ brand products. The spot price is: $c_{03}^{f}(R)=v-\frac{2(n+1)(2-\beta) R}{n+2-\beta}$;

- if $\widehat{R}_{3}(G)<R \leq \check{R}_{3}(G)$, the distributor sells $q^{f}\left(c_{13}^{f}(R, G), G\right)=\frac{v-2 \beta R-G}{2(1-\beta)(n+1)}$ of Fairtrade product, bought at the GMP $G$, and the $n$ brand products. The spot price is :

$$
c_{13}^{f}(R, G)=\frac{(n+1)[(n+2-\beta) v-2(n+1)(2-\beta) R]-(2 n+2-\beta) G)}{n(n+1-\beta)} ;
$$

- if $\check{R}_{3}(G)<R<R^{+}$, the spot market price is null and the distributor sells $q^{f}(0, G)=$ $\frac{(n+1)(1-\beta)(2 n+2-\beta) v-\left[2(n+1)^{2}-(n+1)(n+3) \beta+\beta^{2}\right] G}{2(n+1)^{3}(2-\beta)(1-\beta)}$ of Fairtrade product at the GMP $G$.

In that case, the expected profit of farmers becomes

$$
\begin{aligned}
\mathbb{E}\left(\pi^{f}(G)\right)= & \frac{1}{v / 2}\left[\int_{0}^{\widehat{R}_{3}(G)} c_{03}^{f} q^{f}\left(c_{03}^{f}, c_{03}^{f}\right) d R+\int_{\widehat{R}_{3}(G)}^{\check{R}_{3}(G)} G q^{f}\left(c_{13}^{f}, G\right) d R\right. \\
& \left.+\int_{\check{R}_{3}(G)}^{R^{+}} G q^{f}(0, G) d R\right] .
\end{aligned}
$$

The program ?? has only one positive solution denoted $G_{3}^{*}(n, \beta, v)$ and is defined as follows:

$$
G_{3}^{*}(n, \beta, v)=\frac{(1+n) v(-1+\beta)\left((-2+\beta)^{2}+2 n^{3}(-1+\beta)+5 n^{2} \beta-n\left(-6+\beta+\beta^{2}\right)+\sqrt{Z}\right)}{-8(1+n)^{3}(2+n)+(1+n)^{2}(32+n(24+5 n)) \beta-2(1+n)(10+n(7+3 n)) \beta^{2}+(4+n(2+n)) \beta^{3}}
$$




$$
\begin{aligned}
\text { with } Z= & 4(1+n)^{4}(2+3 n)^{2}-4(1+n)^{3}(2+n)(4+n(13+7 n)) \beta \\
& +(1+n)^{2}\left(24+n\left(108+n\left(101+46 n+4 n^{2}\right)\right)\right) \beta^{2} \\
& -2(1+n)(4+n(21+n(19+10 n))) \beta^{3}+(1+n(6+n(5+2 n))) \beta^{4} .
\end{aligned}
$$

It is positive $\forall n, \beta, v$ and $\left.\frac{d^{2} \mathbb{E}\left(\pi^{f}(G)\right)}{d G^{2}}\right|_{G=G_{3}^{*}}(n, \beta, v)<0$. Note that $G_{3}^{*}(n, \beta, v) \leq v(1-\beta)$ when $\beta<\bar{\beta}(n)$, increasing in $n$, with $\bar{\beta}(2)=0.729345$ and $\lim _{n \rightarrow+\infty} \bar{\beta}(n)=8 / 9$.

(ii). If $v(1-\beta)<G<\bar{G}_{3}(n, \beta, v)$, that is, $\check{R}_{3}(G)<\bar{R}_{3}(G)<R^{+}$,

- if $R \leq \widehat{R}_{3}$, the distributor sells the Fairtrade product in quantity $q^{f}\left(c_{0}^{f}, c_{0}^{f}\right)=\frac{(2 n+2-\beta) R}{(n+1)(n+2-\beta)}$ and the $n$ brand products. The spot price is then $c_{03}^{f}(R)=v-\frac{2(n+1)(2-\beta) R}{n+2-\beta}$;

- if $\widehat{R}_{3}(G)<R \leq \check{R}_{3}(G)$, the distributor sells a quantity $q^{f}\left(c_{1}^{f}, G\right)=\frac{v-2 \beta R-G}{2(1-\beta)(n+1)}$ of Fairtrade product, bought at the GMP $G$, and the $n$ brand products. The spot price is then $c_{13}^{f}(R, G)=\frac{(n+1)[(n+2-\beta) v-2(n+1)(2-\beta) R]-(2 n+2-\beta) G}{n(n+1-\beta)} ;$

- if $\check{R}_{3}(G)<R<\bar{R}_{3}(G)$, the spot market price is null and the distributor sells the quantity of Fairtrade product $q^{f}(0, G)=\frac{(n+1)(1-\beta)(2 n+2-\beta) v-\left[2(n+1)^{2}-(n+1)(n+3) \beta+\beta^{2}\right] G}{2(n+1)^{3}(2-\beta)(1-\beta)}$ at the GMP $G$.

- if $\bar{R}_{3}(G)<R<R^{+}$, the distributor does not sell the Fairtrade product, but only the $n$ brands and the spot price is $c_{3}^{*}$.

The expected profit of the Fairtrade channel farmers:

$$
\begin{aligned}
\mathbb{E}\left(\pi^{f}(G)\right)= & \frac{1}{v / 2}\left[\int_{0}^{\widehat{R}(G)} c_{03}^{f}(R) q^{f}\left(c_{03}^{f}, c_{03}^{f}\right) d R+\int_{\widehat{R}_{3}(G)}^{\check{R}_{3}(G)} G q^{f}\left(c_{13}^{f}, G\right) d R\right. \\
& \left.+\int_{\check{R}_{3}(G)}^{\bar{R}_{3}(G)} G q^{f}(0, G) d R\right] .
\end{aligned}
$$

The program ?? has two solutions which never respect the initial condition, $v(1-\beta)<G<$ $\bar{G}_{3}(n, \beta, v)$. 
(iii). If $G \geq \bar{G}_{3}(n, \beta, v)$, that is, $\widehat{R}_{3}(G)<\bar{R}_{3}(G) \leq \check{R}_{3}(G)$,

- if $R \leq \widehat{R}_{3}$, the distributor sells the Fairtrade product in quantity $q^{f}\left(c_{03}^{f}, c_{03}^{f}\right)=\frac{(2 n+2-\beta) R}{(n+1)(n+2-\beta)}$, bought at the spot price $c_{03}^{f}(R)=v-\frac{2(n+1)(2-\beta) R}{n+2-\beta}$, and the $n$ brand products;

- if $\widehat{R}_{3}(G)<R \leq \bar{R}_{3}$, the distributor sells a quantity $q^{f}\left(c_{13}^{f}, G\right)=\frac{v-2 \beta R-G}{2(1-\beta)(n+1)}$ of Fairtrade product, bought at the GMP $G$, and the $n$ brands. The spot market price is then $c_{13}^{f}(R, G)=\frac{(n+1)[(n+2-\beta) v-2(n+1)(2-\beta) R]-(2 n+2-\beta) G}{n(n+1-\beta)} ;$

- if $\bar{R}_{3}<R<\frac{v}{2}$, the distributor does not sell the Fairtrade product, but only the $n$ brands and the spot price is $c_{3}^{*}$.

Then, the expected profit of the Fairtrade channel farmers is

$$
\mathbb{E}\left(\pi^{f}(G)\right)=\frac{1}{v / 2}\left[\int_{0}^{\widehat{R}_{3}(G)} c_{03}^{f}(R) q^{f}\left(c_{03}^{f}, c_{03}^{f}\right) d R+\int_{\widehat{R}_{3}(G)}^{\bar{R}_{3}(G)} G q^{f}\left(c_{13}^{f}, G\right) d R\right] .
$$

The two solutions of this program ?? are $v$ and $v \frac{(1-\beta)(2 n+2-\beta)}{(6-4 \beta) n+(3-\beta)(2-\beta)}$ and, they never respect the two conditions, $G>\bar{G}_{3}(n, \beta, v)$ and $G<v-2 \beta v$.

\section{A.3.2 Proof of Proposition ??}

It is straightforward to show that $c_{03}^{f}(R)>c_{3}^{*}(R), \forall R \in\left[0, \hat{R}_{3}\left(G_{3}^{*}\right)\right]$.

When $R>\hat{R}_{3}\left(G_{3}^{*}\right), c_{3}^{f}(R)=c_{13}^{f}\left(R, G_{3}^{*}\right)$. All the spot prices are decreasing in $R$ and $\dot{R}_{3}<\widehat{R}_{3}$

for all $n \geq 1, \beta \in(0,1]$ and $v$. Thus, $c_{3}^{*}(R)<c_{13}^{f}\left(R, G_{3}^{*}\right) \forall R<\widehat{R}_{3}$. 